\title{
Consequences of Electron-Density Manipulations on the X-Ray Photoelectron Spectroscopic Properties of Ferrocenyl- $\beta$-diketonato Complexes of Manganese(III). Structure of $\left[\mathrm{Mn}(\mathrm{FcCOCHCOCH})_{3}\right]$
}

Blenerhassitt E. Buitendach, ${ }^{a}$ Elizabeth Erasmus, ${ }^{a}$ Marilé Landman, ${ }^{b}$ J. W(Hans)

Niemantsverdriet, ${ }^{c}$ and Jannie C. Swarts ${ }^{a,}{ }^{*}$

\footnotetext{
${ }^{a}$ Department of Chemistry, University of the Free State, Bloemfontein 9300, South Africa

${ }^{b}$ Department of Chemistry, University of Pretoria, Pretoria, South Africa.

${ }^{c}$ Syngaschem BV, Helix Building, Campus of the Eindhoven University of Technology, Eindhoven, Netherlands.

*Corresponding author Fax: +27 51 4017295; E-mail address: swartsjc@ufs.ac.za
}

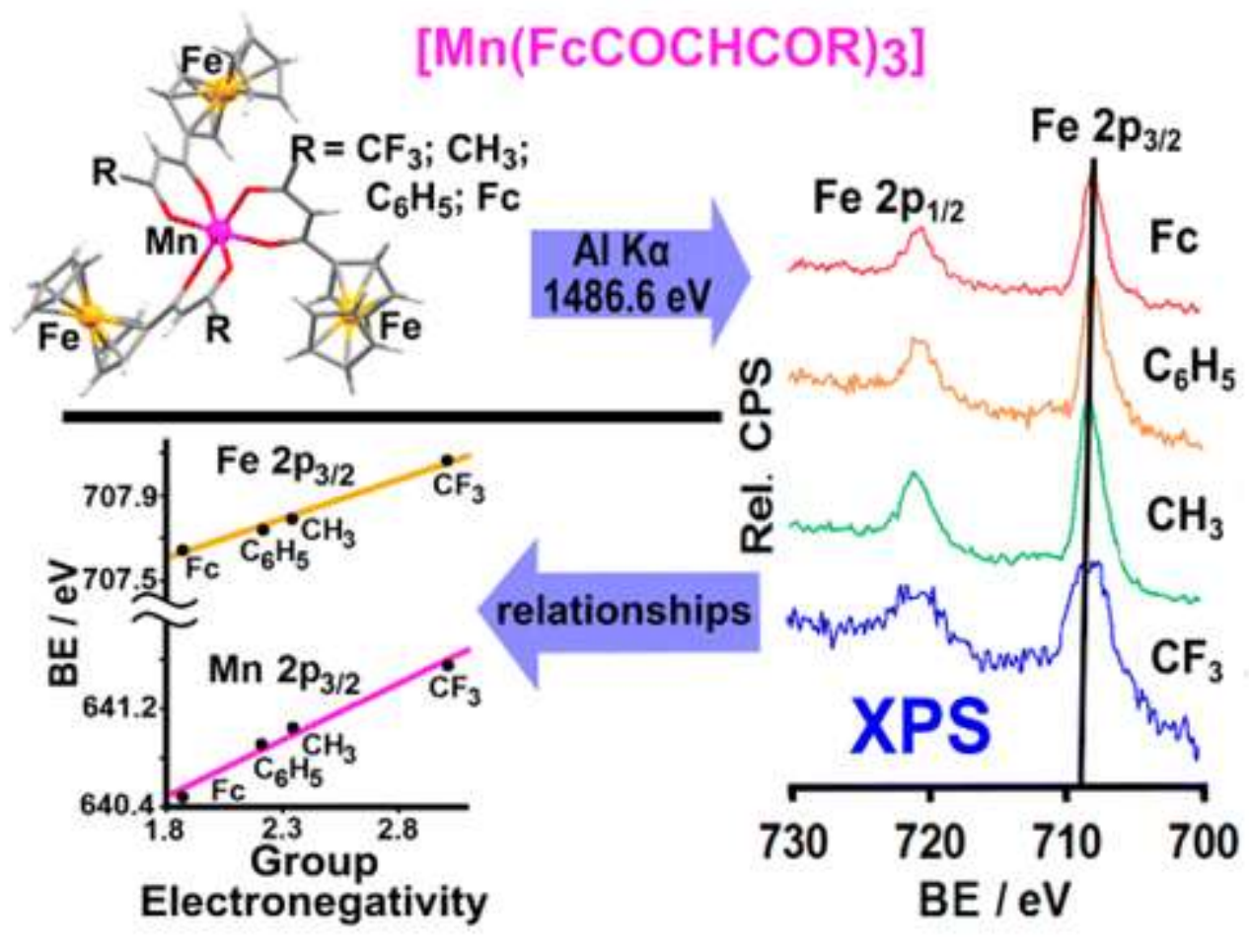


ABSTRACT: Reaction of $\left[\mathrm{Mn}_{3}(\mathrm{OAc})_{6} \mathrm{O} \cdot 3 \mathrm{H}_{2} \mathrm{O}\right]^{+}, \mathbf{1}$, with ferrocenyl $\beta$-diketones of the type FcCOCH $\mathrm{COR}_{2}$ with $\mathrm{R}=\mathrm{CF}_{3}, \mathbf{2} \mathbf{a}, \mathrm{CH}_{3}, \mathbf{2} \mathbf{b}, \mathrm{Ph}=\mathrm{C}_{6} \mathrm{H}_{5}, \mathbf{2} \mathbf{c}$, and $\left.\mathrm{Fc}=\mathrm{Fe}^{\mathrm{II}}\left(\eta^{5}-\mathrm{C}_{5} \mathrm{H}_{4}\right)\left(\eta^{5}-\mathrm{C}_{5} \mathrm{H}_{5}\right), \mathbf{2 d}\right)$, yielded a series of ferrocene-functionalized $\beta$-diketonato manganese(III) complexes $\mathbf{3 a}-\mathbf{3 d}$ of general formula $\left[\mathrm{Mn}(\mathrm{FcCOCHCOR})_{3}\right]$. The mixed ligand $\beta$-diketonato complex $\left[\mathrm{Mn}(\mathrm{FcCOCHCOFc})_{2}\left(\mathrm{FcCOCHCOCH}_{3}\right)\right], \mathbf{4}$, was obtained by reacting mixtures of diketones $\mathbf{2 b}$ and 2d with 1. A single crystal $X$-ray structure determination of $\mathbf{3 b}(\mathrm{Z}=2$, triclinic, space group $P$ 1) highlighted a weak axial elongating Jahn-Teller effect and a high degree of bond conjugation. An X-ray photoelectron spectroscopic study, by virtue of linear relationships between group electronegativities of ligand R groups, $\chi_{R}$, or $\Sigma \chi_{R}$, and binding energies of both the Fe $2 p_{3 / 2}$ and Mn $2 \mathrm{p}_{3 / 2}$ photoelectron lines, confirmed communication between molecular fragments of $\mathbf{2 a}-\mathbf{2 d}$ as well as 3a-3d. This unprecedented observation allows prediction of binding energies from known $\beta$-diketonato side group $\chi_{\mathrm{R}}$ values.

Keywords: Manganese, ferrocene, betadiketonato complexes, substituent effects, electronic spectra, X-ray photoelectron spectroscopy, binding energy predictions.

\section{Introduction}

The first row transition metal, manganese, exhibits a wide variety of oxidation states in compounds ranging from $\mathrm{Mn}(\mathrm{I})$, e.g. $\left[\mathrm{Mn}\left(\mathrm{C}_{5} \mathrm{H}_{5}\right)(\mathrm{CO})_{3}\right],{ }^{1}$ to $\mathrm{Mn}(\mathrm{III})$ complexes like $\left[\mathrm{Mn}(\mathrm{NO})_{3} \mathrm{CO}\right]$, to $\mathrm{Mn}(\mathrm{VII})$, e.g. $\mathrm{KMnO}_{4}{ }^{2}$ Manganese(III) compounds show a wide range of promising applications including drying catalyst for alkyd paints, ${ }^{3}$ oxidation catalysts, ${ }^{4}$ superoxide dismutase mimics ${ }^{5}$ and polynuclear transition metal complexes for single-molecule magnets. ${ }^{6}$ In an octahedral ligand environment, the four unpaired electrons of manganese(III) result in a ${ }^{5} E_{\mathrm{g}}$ ground state, which is 
susceptible to Jahn-Teller distortions. ${ }^{7}$ The volatility and low temperature clean decomposition of various transition metal $\beta$-diketonates, such as those of manganese(III), make them suitable as metal organic chemical vapor deposition precursors. ${ }^{8}$ While there are many homometallic $\beta$ diketonates known as precursors for the preparation of oxide materials, ${ }^{9}$ heterometallic $\beta$ diketonato complexes are relatively rare. ${ }^{10}$ Zanello previously published the synthesis of various first row transition-metal complexes of 1-ferrocenyl-1,3-butanedione, including the Mn(III) complex $\left[\mathrm{Mn}\left(\mathrm{FcCOCHCOCH}_{3}\right)_{3}\right], \mathbf{3 b}^{11}$ The complex was prepared in a comproportionation reaction of $\mathrm{MnCl}_{2}$ with a stoichiometric amount of permanganate in the presence of an excess of $\beta$ diketone. Other ferrocene-containing $\beta$-diketonato complexes of $\mathrm{Mn}(\mathrm{III})$ are hitherto unknown. Due to ferrocene's stability and the ease by which it can be chemically modified, it has frequently found application in new organometallic complexes and functional materials. The ferrocenyl iron(II/III) couple also shows good electrochemical reversibility and as a result ferrocene derivatives are frequently the subject of electrochemical studies. ${ }^{12}$ The rate of oxidative addition reactions has been shown to be enhanced in compounds having the electron-donating ferrocenyl group in its structure. ${ }^{13}$ Ferrocene-containing compounds have also been studied in asymmetric catalysis, ${ }^{14}$ as high combustion rate catalysts, ${ }^{15}$ as nonlinear optical materials, ${ }^{16}$ as donors in energy transfer processes, ${ }^{17}$ and as anticancer drugs. ${ }^{18}$

In this study we report the synthesis, utilizing a new synthetic pathway, and characterization of known and new ferrocene-containing $\beta$-diketonato complexes of manganese(III), $\left[\mathrm{Mn}(\mathrm{FcCOCHCOR})_{3}\right]$, with $\mathrm{R}=\mathrm{CH}_{3}$ (Zanello's compound), $\mathrm{CF}_{3}, \mathrm{C}_{6} \mathrm{H}_{5}$, and Fc (ferrocenyl = $\left.\mathrm{Fe}^{\mathrm{II}}\left(\eta^{5}-\mathrm{C}_{5} \mathrm{H}_{4}\right)\left(\eta^{5}-\mathrm{C}_{5} \mathrm{H}_{5}\right)\right)$ as well as the mixed ligand complex $\left[\mathrm{Mn}(\mathrm{FcCOCHCOFc})_{2}(\mathrm{FcCOCHCOCH} 3)\right], \mathbf{4}$, and describe the crystal structure of $\mathbf{3 b}$. Utilizing the concept of group electronegativities ${ }^{19}$ as a function of relative molecular fragment electron density, 
we then highlight intramolecular communication between molecular fragments of $\mathbf{3 a}-\mathbf{3 d}$ from results of an X-ray photoelectron spectroscopic (XPS) study.

\section{Results and discussion}

\subsection{Synthesis and characterization}

The ferrocene-containing manganese(III) $\beta$-diketonates $\left[\mathrm{Mn}(\mathrm{FcCOCHCOR})_{3}\right]$ with $\mathrm{R}=\mathrm{CF}_{3}(\mathbf{3 a})$, $\mathrm{CH}_{3}(\mathbf{3 b}), \mathrm{Ph}=\mathrm{C}_{6} \mathrm{H}_{5}(\mathbf{3 c})$ and $\mathrm{Fc}=\mathrm{Fe}\left(\eta^{5}-\mathrm{C}_{5} \mathrm{H}_{4}\right)\left(\eta^{5}-\mathrm{C}_{5} \mathrm{H}_{5}\right)(\mathbf{3 d})$ were prepared as shown in Scheme 1. The free $\beta$-diketones $\mathrm{FcCOCH}_{2} \mathrm{COR}\left(\mathbf{2 a}, \mathrm{R}=\mathrm{CF}_{3} ; \mathbf{2 b}, \mathrm{R}=\mathrm{CH}_{3} ; \mathbf{2 c}, \mathrm{R}=\mathrm{Ph}\right.$ and $\left.\mathbf{2 d}, \mathrm{R}=\mathrm{Fc}\right)$ were reacted with the circular trimeric manganese(III) complex $\left[\mathrm{Mn}_{3}(\mathrm{OAc})_{6} \mathrm{O} \cdot 3 \mathrm{H}_{2} \mathrm{O}\right]^{+}, \mathbf{1},{ }^{20}$ in the presence of sodium acetate in a mixture of acetone-water in the ratio 3:1. After work-up, the
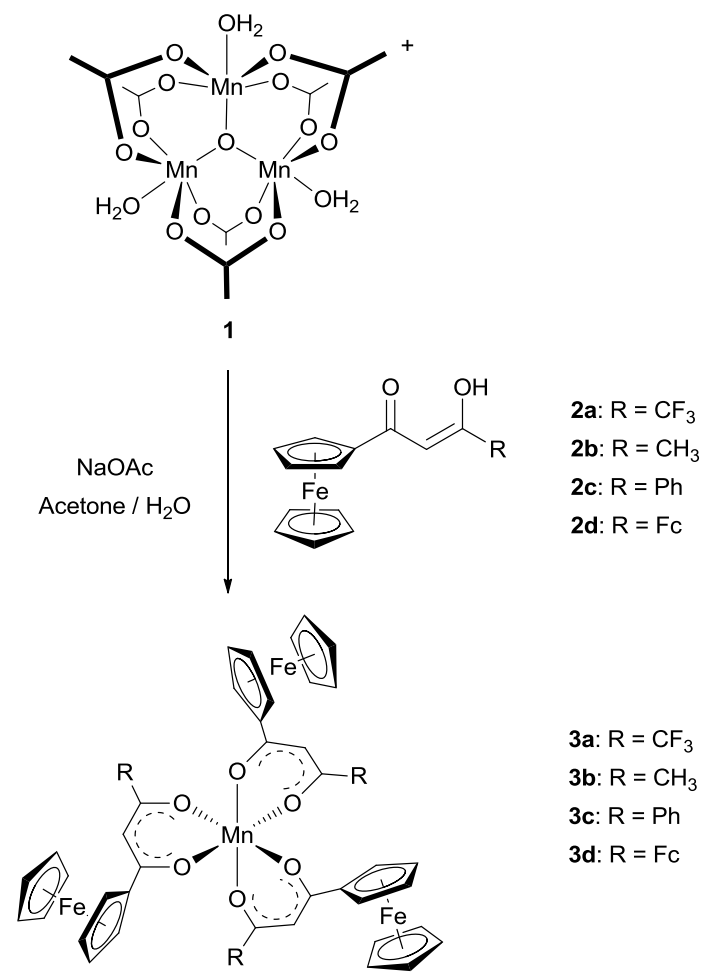

Scheme 1 Synthesis of octahedral tris( $\beta$-diketonato)-manganese(III) complexes $\mathbf{3 a}-\mathbf{3 d}$ from the circular trimeric manganese(III) acetate complex, 1. Fac isomers of $\mathbf{3 a}-\mathbf{3 c}$ are shown but it is 
expected that in the bulk of the products a mixture of mer and fac isomers may exist similar to what was found in diamagnetic aluminium $\beta$-diketonato complexes. ${ }^{21}$

manganese(III) $\beta$-diketonate complexes 3a-3d could be isolated as dark maroon solids in moderate (30-60\%) yields. Complexes 3a-3c are soluble in most organic solvents. However, the hexa ferrocene-containing complex $\mathbf{3 d}$ is only sparingly soluble in most solvents $\left(<0.2 \mathrm{mM}\right.$ in $\mathrm{CH}_{2} \mathrm{Cl}_{2}$ ), but it is moderately soluble in hot toluene.

Complex 4, $\left[\mathrm{Mn}(\mathrm{FcCOCHCOFc})_{2}\left(\mathrm{FcCOCHCOCH}_{3}\right)\right]$, was prepared in a similar method to 3a-3d but by reacting 1 with a 1:2 equivalents mixture of $\beta$-diketones $2 \mathbf{d}(\mathrm{R}=\mathrm{Fc})$ and $\mathbf{2 b}\left(\mathrm{R}=\mathrm{CH}_{3}\right)$ respectively. Complex 4 is well soluble in common organic solvents (> $2 \mathrm{mM}$ in DCM). Increasing the $\beta$-diketone reactant ratio for $\mathbf{2 d : 2 b}=\left[\left(\mathrm{FcCOCH}_{2} \mathrm{COFc}\right)\right]:\left[\left(\mathrm{FcCOCH}_{2} \mathrm{COCH}_{3}\right)\right]$ to 1:4 still yielded only complex $\mathbf{4}$ as a mixed ligand product. No $\left[\mathrm{Mn}(\mathrm{FcCOCHCOFc})(\mathrm{FcCOCHCOCH})_{2}\right]$ could be identified. This result is consistent with $\mathrm{Mn}(\mathrm{III})$ having a greater affinity for the stronger electron-donating ligand $(\mathrm{FcCOCHCOFc})^{-}, \mathbf{2 d}^{-}$, than for the weaker electron-donating ligand $(\mathrm{FcCOCHCOCH} 3)^{-}, \mathbf{2} \mathbf{b}^{-}$. That $\mathbf{2} \mathbf{d}^{-}$as a ligand is more electron-donating than $\mathbf{2 b}^{-}$is easy recognizable (and quantifiable) by comparing the group electronegativity, $\chi_{\mathrm{R}}$, of the ferrocenyl group $\left(\chi_{\mathrm{Fc}}=1.87\right)$ with that of the methyl group $\left(\chi_{\mathrm{CH} 3}=\right.$ 2.30). The more electron-withdrawing an R-group is, the larger is $\chi_{R}$. For example, on the Pauling scale of atom electronegativities, $\chi_{\mathrm{F}}$ of $\mathrm{F}$ is 4 , the highest possible value. To understand why no $\mathbf{3 d}$, $\left[\mathrm{Mn}(\mathrm{FcCOCHCOFc})_{3}\right]$, was isolated in these mixed-ligand coordination reactions, it can be noted that $\mathbf{2 d}, \mathrm{FcCOCH}_{2} \mathrm{COFc}$, which has two large ferrocenyl groups attached to it, is more sterically hindered compared to $\mathbf{2 b}$, $\mathrm{FcCOCH}_{2} \mathrm{COCH}_{3}$, which has just one ferrocenyl substituent as well as 
the much smaller $\mathrm{CH}_{3}$ substituent. Therefore it is reasonable to expect that during complexation, once the intermediate $\left[\mathrm{Mn}(\mathrm{FcCOCHCOFc})_{2}\right]^{+}$fragment has formed, complexation with the less crowded $\beta$-diketone $\mathbf{2 b}$ is kinetically favoured over complexation with $\mathbf{2 d}$.

IR spectra of 3a-3d and $\mathbf{4}$ displayed the characteristic strong $v_{\mathrm{CO}}$ vibrations found between $1498-$ $1572 \mathrm{~cm}^{-1}$ (Experimental Part) which is typical for chelate-bonded $\beta$-diketonato ligands in transition metal chemistry. ${ }^{22}$ A shift to lower wave numbers is observed for $\mathbf{3 a} \mathbf{a} \mathbf{3 d}$ and $\mathbf{4}$ compared to the free $\beta$-diketones $\mathbf{2 a}-\mathbf{2 d}\left(1620-1710 \mathrm{~cm}^{-1}\right)^{23}$ which allows the monitoring of the reaction progress. Prominent $\mathrm{CH}$-stretching bands are also observed at ca. $3100 \mathrm{~cm}^{-1}$. Peak maxima of the UV-Vis spectra of complexes 3a-3d and $\mathbf{4}$ (Figure 1) are summarized in Table 1. Dichloromethane solutions of the highly soluble complexes $\mathbf{3 a}-\mathbf{3 c}$ and $\mathbf{4}$ all showed relatively high extinction coefficients. All complexes followed the Beer-Lambert law, $\mathrm{A}=\varepsilon \mathrm{Cl}$, which implies a linear relationship between absorbance and concentration.

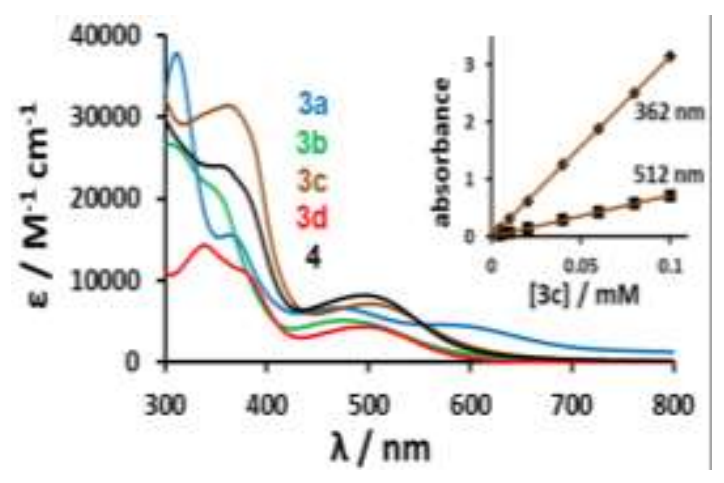

Figure 1. UV-Vis spectra of $\left[\mathrm{Mn}(\mathrm{FcCOCHCOR})_{3}\right]$ complexes $\mathbf{3 a}\left(\mathrm{R}=\mathrm{CF}_{3}\right.$, blue $), \mathbf{3 b}\left(\mathrm{R}=\mathrm{CH}_{3}\right.$, green $), \mathbf{3} \mathbf{c}(\mathrm{R}=\mathrm{Ph}$, orange), all from $0.1 \mathrm{mM}$ solutions, and $\mathbf{3 d}(\mathrm{R}=\mathrm{Fc}$, red) from a $0.01 \mathrm{mM}$ solution; as well as complex $\left[\mathrm{Mn}(\mathrm{FcCOCHCOFc})_{2}\left(\mathrm{FcCOCHCOCH}_{3}\right)\right](4$, black, $0.1 \mathrm{mM})$ in $\mathrm{CH}_{2} \mathrm{Cl}_{2}$. Insert: Linear relationship between absorbance and concentration for $\mathbf{3 c}$ at $\lambda=362$ and $512 \mathrm{~nm}$. 
Table 1: Wavelengths $\left(\lambda_{\max }\right)$ and extinction coefficients, $\varepsilon$, of $U V-V i s$ bands of $\left[\mathrm{Mn}(\mathrm{FcCOCHCOR})_{3}\right]$ complexes 3a-3d and 4 in $\mathrm{CH}_{2} \mathrm{Cl}_{2}$.

\begin{tabular}{|c|c|}
\hline Compound & $\lambda_{\max } / \mathrm{nm}\left(\varepsilon / \mathrm{M}^{-1} \mathrm{~cm}^{-1}\right)$ \\
\hline 3a: $\mathbf{R}=3 \mathbf{x C F}_{3}$ & 312 (37812); 363 (15564); 469 (6676); 583 (4300) \\
\hline 3b: $\mathbf{R}=3 \mathbf{x C H}_{3}$ & 303 (26695); 350 (20982); 475 (5118) \\
\hline 3c: $\mathbf{R}=3 \times \mathbf{P h}$ & $362(31433) ; 502(7138)$ \\
\hline 3d: $\mathbf{R}=\mathbf{3 x F c}$ & 339 (14341); 380 (10890); 498 (4345) \\
\hline 4: $R=\left(1 \times C_{3}\right)+(2 x F c)^{a}$ & 354 (4002); 496 (8198) \\
\hline
\end{tabular}

The low energy band that was observed for $\left[\mathrm{Mn}\left(\mathrm{FcCOCHCOCF}_{3}\right)_{3}\right]$, 3a, at ca. $583 \mathrm{~nm}$ was not clearly observed for the other complexes, probably because their intensities were not strong enough (i.e. a low $\varepsilon$ value). This band is not unknown in $\mathrm{CF}_{3}$ containing $\beta$-diketonato systems;

Van der Zeiden ${ }^{24}$ reported a similar lower energy band in tungsten( 0$) \beta$-diketonato complexes and assigned it to a MLCT band with destabilized $\mathrm{t}_{2 \mathrm{~g}}$ level after appropriate calculations.

\subsection{Single Crystal $X$-ray structure of $\mathbf{3 b}$}

To understand the trends observed in XPS-obtained binding energies for Fe(II) (and also Mn(III)) of complexes $\mathbf{3 a}-\mathbf{3 d}$ described in the next section, an evaluation of the structural characteristics of $\mathbf{3 b}$ is useful. The fac isomer of complex $\mathbf{3 b}$ crystallized from toluene in the triclinic space group $P-1$ having ca. 1 disordered solvent molecule for every two molecules of $\mathbf{3 b}$. The refinement parameters and crystal data are summarized in Table 2 and the molecular structure of $\mathbf{3 b}$, highlighting atom labeling, are shown in Figure 2. Selected bond distances and bond angles are summarized in the caption of Figure 2, but the full set of bond lengths and angles is available in Supplementary Information. 


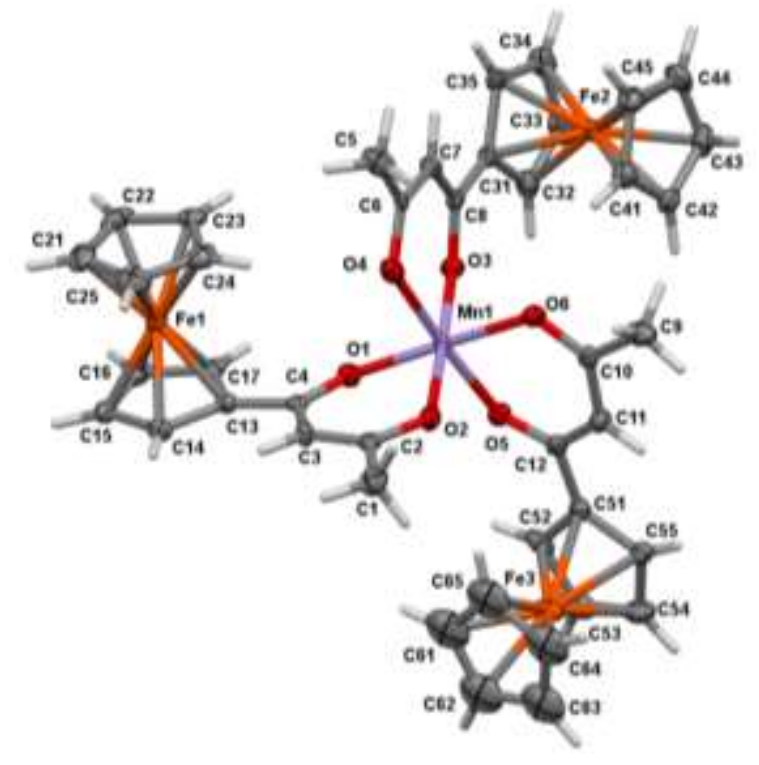

Figure 2. Molecular structure of $\left[\mathrm{Mn}\left(\mathrm{FcCOCHCOCH}_{3}\right)_{3}\right], \mathbf{3 b}$, showing atom labeling. Selected bond distances $(\AA)$ and angles (deg) are: $\mathrm{Mn}(1)-\mathrm{O}(1)$ 1.984(3), $\mathrm{Mn}(1)-\mathrm{O}(2)$ 1.991(3), $\mathrm{Mn}(1)-\mathrm{O}(3)$ 1.994(3), $\mathrm{Mn}(1)-\mathrm{O}(4) 2.018(3)$, $\mathrm{Mn}(1)-\mathrm{O}(5)$ 2.014(3), $\mathrm{Mn}(1)-\mathrm{O}(6) 1.979(3), \mathrm{Fe}(1)-\mathrm{C}(13)$ 2.030(5), $\mathrm{O}(1)-\mathrm{C}(4)$ 1.278(5), $\mathrm{O}(2)-\mathrm{C}(2)$ 1.283(5), $\mathrm{O}(3)-\mathrm{C}(8)$ 1.291(5), O(4)-C(6) 1.291(5), $\mathrm{O}(5)-\mathrm{C}(12)$ 1.276(5), $\mathrm{O}(6)-\mathrm{C}(10)$ 1.287(5), $\mathrm{C}(1)-\mathrm{C}(2) 1.485(7), \mathrm{C}(2)-\mathrm{C}(3)$ 1.390(6), C(3)-C(4) 1.401(6), C(4)-C(13) 1.473(6), C(13)-C(14) 1.440(7), C(14)-C(15) 1.404(7), C(15)-C(16) 1.416(8), C(16)-C(17) 1.418(7), C(13)-C(17) 1.425(7), C(21)-C(22) 1.405(8), C(21)-C(25) 1.423(8), C(22)-C(23) 1.415(7), C(23)-C(24) 1.412(7), C(24)- $\mathrm{C}(25)$ 1.414(7); O(1)-Mn(1)-O(6) 175.93(13), O(4)-Mn(1)-O(5) 175.87(13), O(1)-Mn(1)-O(3) 91.58(13), O(3)-Mn(1)-O(6) 92.15(13), C(4)-O(1)-Mn(1) 125.3(3), $\mathrm{C}(2)-\mathrm{O}(2)-\mathrm{Mn}(1)$ 125.7(3), C(1)-C(2)-C(3) 120.4(4), C(2)-C(3)-C(4) 124.3(4), C(3)-C(4)-C(13) 119.2(4), $\mathrm{C}(14)-\mathrm{C}(13)-\mathrm{C}(17)$ 107.5(4), $\mathrm{C}(13)-\mathrm{C}(14)-\mathrm{C}(15)$ 107.7(5), C(14)-C(15)-C(16) 108.9(5), C(15)-C(16)-C(17) 108.0(5), $\mathrm{C}(16)-\mathrm{C}(17)-\mathrm{C}(13)$ 107.9(5), $\mathrm{C}(25)-\mathrm{C}(21)-\mathrm{C}(22)$ 108.1(5), $\mathrm{C}(21)-\mathrm{C}(22)-\mathrm{C}(23)$ 108.2(5), $\mathrm{C}(22)-\mathrm{C}(23)-\mathrm{C}(24)$ 108.0(5), $\mathrm{C}(23)-\mathrm{C}(24)-\mathrm{C}(25)$ 108.2(5), C(24)-C(25)-C(21) 107.6(5), O(1)-C(4)-C(3) 124.8(4), $\mathrm{O}(1)-\mathrm{C}(4)-\mathrm{C}(13)$ 116.0(4), $\mathrm{O}(2)-\mathrm{C}(2)-\mathrm{C}(3)$ 124.1(4), $\mathrm{O}(1)-\mathrm{C}(4)-\mathrm{C}(13)$ 116.0(4), $\mathrm{O}(2)-\mathrm{C}(2)-\mathrm{C}(1)$ 115.4(4). Other bond lengths and angels are available in Supplementary Information. Symmetry transformations used to generate equivalent atoms: \#1 -x,-y,-z

Typical C-C single bond lengths range from 1.38 (sp-sp: $-\mathrm{C} \equiv \mathrm{C}-\mathrm{C} \equiv \mathrm{C}-$ ) to $1.53 \AA$ ( $\mathrm{sp}^{3}-\mathrm{sp}^{3}$ : $-\mathrm{C}-\mathrm{C}-$ ), while double bonds range from 1.28 (sp-sp: $=\mathrm{C}=\mathrm{C}=$ ) to $1.32 \AA$ ( $\mathrm{sp}^{2}-\mathrm{sp}^{2}$ : $-\mathrm{C}=\mathrm{C}-{ }^{25}{ }^{25}$ The $\mathrm{C}-\mathrm{C}$ bonds in compounds showing delocalization are expected to have bond distances that lie between the $1.48 \AA$ of an $\mathrm{sp}^{2}-\mathrm{sp}^{2}=\mathrm{C}-\mathrm{C}=$ single bond and the $1.32 \AA$ of an $\mathrm{sp}^{2}-\mathrm{sp}^{2}-\mathrm{C}=\mathrm{C}$ - double bond. ${ }^{26}$ All the $\mathrm{C}-\mathrm{C}$ bonds in the $\beta$-diketonato pseudo-aromatic backbone fall within these limits, but the three $\beta$ - 
diketonato ligands are not identical. The shortest bonds are $\mathrm{C}(2)-\mathrm{C}(3)$ and $\mathrm{C}(7)-\mathrm{C}(8)$ (both 1.390(6) $\AA$ ), while the longest is $\mathrm{C}(6)-\mathrm{C}(7)$ with $l=1.424(7) \AA$. As expected, the longest $\mathrm{C}$-C bond length in the ligand (1.485(7) $\AA$ ) belongs to a $\mathrm{C}-\mathrm{CH}_{3}$ side chain: bond $\mathrm{C}(1)-\mathrm{C}(2)$. This highlights the $\mathrm{C}-\mathrm{CH}_{3}$ side chain conjugates weakly into the pseudo-aromatic $\beta$-diketonato backbone. Notably though, are the shorter bond lengths of bonds linking the ferrocenyl group to the pseudo-aromatic ligand backbone (e.g. $l=1.472(6)$ for $\mathrm{C}(8)-\mathrm{C}(31)$ ). It follows that the aromatic ferrocenyl group conjugates slightly better into the $\beta$-diketonato backbone. The difference between the two $\mathrm{C}-\mathrm{C}$ bond lengths around the methine $(\mathrm{CH})$ group in the $(\mathrm{O}) \mathrm{C}-\mathrm{CH}-\mathrm{C}(\mathrm{O})$ backbone of the $\beta$-diketonato ligands identified by $\mathrm{Fe}(1), \mathrm{Fe}(2)$, and $\mathrm{Fe}(3)$ are $0.011,0.034$, and $0.007 \AA$, respectively. Thus, the $\mathrm{Fe}(2) \beta$-diketonato fragment is the most asymmetric while the $\mathrm{Fe}(1)$ and $\mathrm{Fe}(3) \beta$-diketonato fragments are for all practical purposes symmetric. However, all $\mathrm{C}-\mathrm{C}$ bonds in each of the $\beta$ diketonato backbones have delocalized character and should in principle be capable of conveying any electron-withdrawing and electron-donating effects of R-substituents to and from the ferrocenyl group of the ligand.

Regarding the ferrocenyl groups, the average $\mathrm{C}-\mathrm{C}$ bond distance within the ferrocenyl groups is $1.409 \AA$ for the unsubstituted cyclopentadienyl rings and $1.421 \AA$ for substituted cyclopentadienyl rings. The largest deviations from this average is $+0.019 \AA$ for $\mathrm{C}(13)-\mathrm{C}(14)$, and $-0.024 \AA$ for bond $\mathrm{C}(62)-\mathrm{C}(63)$. Bond angles in both the unsubstituted and the substituted cyclopentadienyl rings averaged $108^{\circ}$, the ideal theoretical value. The largest deviations from the average values were $\mathrm{C}(61)-\mathrm{C}(62)-\mathrm{C}(63)\left(+2.0^{\circ}\right)$ and $\mathrm{C}(62)-\mathrm{C}(63)-\mathrm{C}(64)\left(-1.5^{\circ}\right)$ on the unsubstituted $\mathrm{Cp}$ ring coordinated to $\mathrm{Fe}(3)$. Each of the separate ferrocenyl groups thus exhibits the expected normal delocalized bond lengths and angles. All three ferrocenyl groups were found to exist almost exactly in the eclipsed form. The deviation from eclipsed form, as measured with the dihedral 
angles $($ cent $=$ centroid $) \mathrm{C}(24)-\operatorname{cent}(\mathrm{Cp}$-ring $)-\operatorname{cent}($ subst-Cp-ring $)-\mathrm{C}(13), \mathrm{C}(41)-$ cent $(\mathrm{Cp}-$ ring $)-$ cent(subst-Cp- ring) $-\mathrm{C}(31)$ and $\mathrm{C}(65)-\operatorname{cent}\left(\mathrm{Cp}\right.$-ring)-cent(subst-Cp-ring) $-\mathrm{C}(51)$, were $-3.90^{\circ}$, $3.32^{\circ}$, and $-1.48^{\circ}$, respectively.

Table 2: Crystal data and structural refinement for $\mathbf{3 b}$.

\begin{tabular}{|c|c|c|c|}
\hline Empirical formula $^{a}$ & $\mathrm{C}_{45.29} \mathrm{H}_{42.29} \mathrm{Fe}_{3} \mathrm{MnO}_{6}{ }^{\mathrm{a}}$ & Absorption coefficient $/ \mathrm{mm}^{-1}$ & 1.493 \\
\hline Molecular weight & 905.11 & $\theta$ range for data collection/deg & 2.512 to 25.679 \\
\hline Crystal size $/ \mathrm{mm}^{3}$ & $0.406 \times 0.208 \times 0.206$ & Index ranges & $-13 \leq h \leq 13$ \\
\hline Temperature/K & $150(2)$ & & $-17 \leq k \leq 17$ \\
\hline Wavelength/Å & 0.71073 & & $-18 \leq l \leq 18$ \\
\hline Crystal system & Triclinic & Reflections collected & 66050 \\
\hline Space group & $P-1$ & Independent reflections & $7212[\mathrm{R}(\mathrm{int})=0.1009]$ \\
\hline & $\mathrm{c}=14.9765(5) ; \gamma=107.047(2)$ & Data/restraints/parameters & 7212 / 0 / 484 \\
\hline Volume $/ \AA^{3}$ & $1901.60(11)$ & Goodness-of-fit on $F^{2}$ & 1.024 \\
\hline $\mathrm{Z}$ & 2 & Final $\mathrm{R}$ indices $[I>2 \sigma(I)]$ & $R 1=0.0534, w R 2=0.1138$ \\
\hline Density (calculated)/ $\mathrm{Mgm}^{-3}$ & 1.581 & $\mathrm{R}$ indices (all data) & $R 1=0.0795, w R 2=0.1263$ \\
\hline $\mathrm{F}(000)$ & 930 & Largest diff. peak and hole/e $\AA^{-3}$ & 1.447 and -1.132 \\
\hline
\end{tabular}

${ }^{\mathrm{a}}$ The molecular formula is not $\mathrm{C}_{42} \mathrm{H}_{39} \mathrm{Fe}_{3} \mathrm{MnO}_{6}$ (formula of pure $3 \mathbf{b}$ ) as ca. $1 / 2$ solvent molecule (toluene) is found for every molecule of $\mathbf{3 b}$. It is highly disordered with the inversion centre at the centre of the six-membered ring. The site occupancy of the toluene molecule was refined to a value of 0.9414 . The reported empirical formula reflects this composition. Symmetry transformations used to generate equivalent atoms: \#1 -x,-y,-z.

To interpret the observed the measured $\mathrm{Mn}-\mathrm{O}$ bonds of $\mathbf{3 b}$, it is first instructive to note that $\mathrm{Mn}-\mathrm{O}$ bonds between $\mathrm{Mn}$ and the $\mathrm{O}$ of an alkoxy group, where no conjugation is possible at all, is typically longer than $1.857 \AA{ }^{27}$ Typical unconjugated $\mathrm{C}=\mathrm{O}$ bond lengths in $\beta$-diketones are 1.206 $\AA$, while $\mathrm{C}-\mathrm{O}$ bond lengths are $1.300 \AA{ }^{28}$ For $\mathbf{3 b}$, all the $\mathrm{C}-\mathrm{O}$ bonds lengths are between these alkoxy and $\mathrm{C}=\mathrm{O}$ bondlength extremes. The shortest is $\mathrm{C}(12)-\mathrm{O}(5)$ with a length of $1.276(5) \AA$ and the longest is $\mathrm{C}(6)-\mathrm{O}(4)$ and $\mathrm{C}(8)-\mathrm{O}(3)$ with $l=1.291(5) \AA$. The difference between the longest and shortest $\mathrm{C}-\mathrm{O}$ bonds is $0.015 \AA$, while the difference between unconjugated $\mathrm{C}=\mathrm{O}$ and $\mathrm{C}-\mathrm{O}$ bonds in $\beta$-diketones is $0.094 \AA$. The $\mathrm{C}-\mathrm{O}$ bonds encountered in $\mathbf{3 b}$ are thus also indicative of significant delocalized character in all three $\beta$-diketonato fragments. 
The manganese atom in $\left[\mathrm{Mn}(\mathrm{FcCOCHCOCH})_{3}\right], \mathbf{3 b}$, has an octahedral coordination sphere. In transition-metal complexes with octahedral ligand fields, the five d-orbitals of the metal atom are split into two groups, a triply degenerate $t_{2 g}$ set and a doubly degenerate $e_{g}$ set, of which the latter contains the orbitals oriented toward the ligands, $d_{x} 2-y 2$ and $d_{z} 2$. [Mn( $\beta$-diketonato $\left.)_{3}\right]$ complexes are high spin $\mathrm{d}^{4}$ complexes that exhibit Jahn-Teller distortion, due to the one electron in the $\mathrm{e}_{\mathrm{g}}$ orbital group, which could either be of $\mathrm{d}_{\mathrm{x}} 2{ }_{-\mathrm{y}} 2$ or $\mathrm{d}_{\mathrm{z}} 2$ character. ${ }^{29}$ The electron occupations $\mathrm{t}_{\mathrm{g}}{ }^{3} \mathrm{~d}_{\mathrm{x}}{ }^{2}{ }_{-\mathrm{y}} 2$ $\mathrm{d}_{\mathrm{z}}^{0} 2$ and $\mathrm{t}_{\mathrm{g}}{ }^{3} \mathrm{~d}^{0}{ }_{\mathrm{x}} 2{ }_{-\mathrm{y}} 2 \mathrm{~d}_{\mathrm{z}}{ }^{2}$, are thus of comparable energy. ${ }^{30}$ When a molecule exhibits a spatially degenerate electronic ground state, it will undergo a geometrical distortion (reduction in symmetry) that removes this degeneracy to lower the overall energy of the species. This distortion was observed in $\mathbf{3 b}$ as an axial elongation Jahn-Teller distortion similar to other $[\mathrm{Mn}(\beta-$ diketonato $)_{3}$ ] complexes. ${ }^{31}$ Axial $\mathrm{Mn}-\mathrm{O}(4)$ and $\mathrm{Mn}-\mathrm{O}(5)$ bond lengths are 2.018(3) and 2.014(3) $\AA$ A respectively while the equatorial $\mathrm{Mn}-\mathrm{O}$ bonds average $1.987 \AA$. The largest deviations from this equatorial average is $-0.008 \AA$ for $\mathrm{Mn}-\mathrm{O}(6)$ which has a bond length of $1.979(3)$. The difference between the largest axial ( $\mathrm{Mn}-\mathrm{O}(4))$ and smallest equatorial $(\mathrm{Mn}-\mathrm{O}(6)) \mathrm{Mn}-\mathrm{O}$ bond length is $0.039 \AA$ A. To compare $3 \mathbf{b}$ with known literature compounds, $\left[\mathrm{Mn}(\mathrm{acac})_{3}\right]$ has average equatorial $\mathrm{Mn}-\mathrm{O}$ bonding distances of $1.935 \AA$ and axial $\mathrm{Mn}-\mathrm{O}$ bonding distances of $2.111 \AA$ for the $\gamma$ polymorph, showing axial Mn-O bond elongation. The $\beta$-polymorph, however, has average equatorial Mn-O bonding distances of $2.000 \AA$ and axial Mn-O distances of $1.943 \AA$, showing axial compression. ${ }^{31 c}$ From this literature result it appears the effects of axial elongation are noticeably more significant than the effects of axial compression. The average $\mathrm{O}-\mathrm{Mn}-\mathrm{O}$ bond angle is $90.00^{\circ}$ with the largest deviation from the average being $3.67^{\circ}$ for $\mathrm{O}(1)-\mathrm{Mn}-\mathrm{O}(5)$. These values are in close agreement with literature values. ${ }^{31}$ The close agreement of all the $\mathrm{Mn}-\mathrm{O}$ bond lengths and angles suggests that electronic communication will be possible through the Mn core of 3b. This means, because of all the conjugated bonds, $\mathbf{3 b}$ should in principle be able to transmit 
electronic effects from one molecular fragment to another. The capability of $\mathbf{3 b}$ to transmit electronic effects from one end of the molecule to the other was studied and quantified with mathematical formulas in the X-ray photoelectron spectroscopy section of this study.

\subsection{X-ray photoelectron spectroscopy}

X-ray photoelectron spectroscopy (XPS) is a useful tool to determine elements present in a sample, the oxidation state of the elements and even the chemical environment which surrounds the element. In our ongoing studies to determine relationships between relative molecular fragment electron-withdrawing or electron-donating properties, expressed as the Gordy group electronegativity of various R-groups ${ }^{19}$ (molecular fragments), $\chi_{R}$, and other physical properties of compound series such as ferrocenyl-containing $\beta$-diketones, $\mathrm{FcCOCH}_{2} \mathrm{COR}$, and their complexes, it has been found that $\chi_{R}$ of the R-groups influences not only the electrochemistry, ${ }^{32}$ but also reaction kinetics ${ }^{13}$ and NMR peak positions. ${ }^{22 b}$ Here we first describe the influence of $\chi_{R}$ on XPS measured binding energies of the Fe $2 p$ peaks of the ferrocene-containing $\beta$-diketones $\mathbf{2 a}-\mathbf{2 d}$ and on $\mathrm{FcCOCH}_{2} \mathrm{COC}_{6} \mathrm{~F}_{5}, \mathbf{2 e}$, and then expand the concept to $\left[\mathrm{Mn}(\mathrm{FcCOCHCOR})_{3}\right]$ complexes 3a-3d. The Fe $2 p_{1 / 2}$ and $\mathrm{Fe} 2 \mathrm{p}_{3 / 2}$ photoelectron peaks of the ferrous $\mathrm{Fe}^{2+}$ ions of the ferrocenyl moiety of $\beta$-diketones 2a-2e gave sharp well-defined peaks. A single Gaussian peak with a full width at half maximum (FWHM) of ca. $1.7 \mathrm{eV}$ was fitted onto each of them (Fig. 3, left). The sharpness of the peak is due to the low spin state of the Fe(II) present in ferrocene, ${ }^{33}$ and it supports the expectation that only one iron specie is present in each of the ferrocene-containing $\beta$-diketones. ${ }^{34}$ The Fe $2 p_{3 / 2}$ photoelectron line was located at ca. $708 \mathrm{eV}$, charge corrected against C $1 \mathrm{~s}$ at $284.8 \mathrm{eV}$ (the lowest binding energy of the fitted adventitious $\mathrm{C} 1 \mathrm{~s}$ peak ${ }^{35}$ ), with spin orbit splitting between the Fe $2 \mathrm{p}_{3 / 2}$ and Fe $2 \mathrm{p}_{1 / 2}$ levels of $13.6 \mathrm{eV}$ (see Table 3 ). This binding energy obtained for all the Fe $2 \mathrm{p}_{3 / 2}$ 
photoelectron lines was found in the large range of 708.03-708.40 eV and spans $0.37 \mathrm{eV}$. This binding energy range, caused by inductive electronic effects of substituents, is large. A full iron redox state change from $\mathrm{Fe}^{2+}$ to $\mathrm{Fe}^{3+}$ would, for example, represent a $1 \mathrm{eV}$ binding energy change. The observed binding energy range is also in good agreement with published values for neat ferrocene $(707.8 \mathrm{eV})^{36}$ and for ferrocene on $\mathrm{Ag}(100)(707.9 \mathrm{eV})^{37}$ but it is lower than the binding energy of a ferrocenyl linked via an aminoalkyl silane onto silicon $(709.7 \mathrm{eV}){ }^{38}$
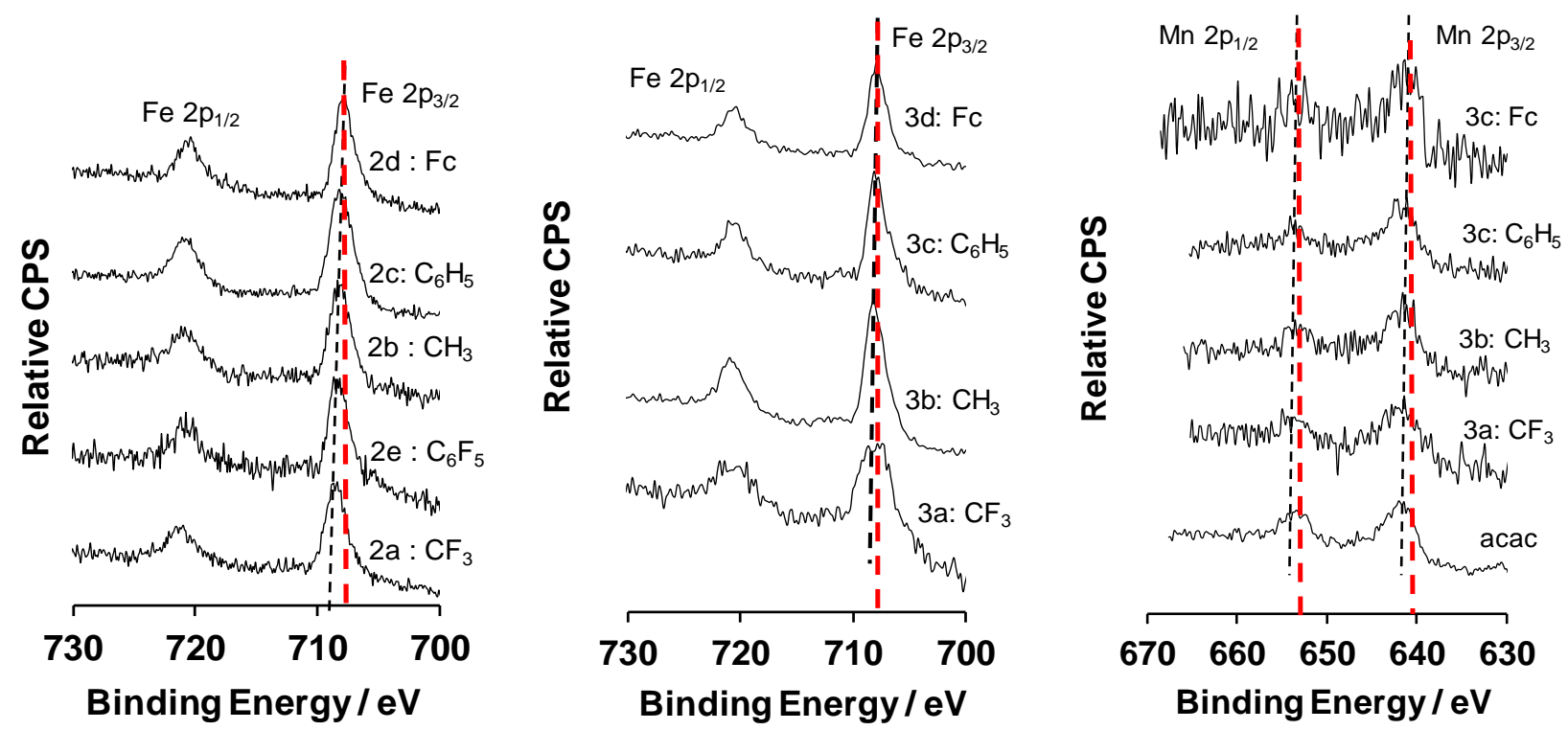

Figure 3. Comparative XPS spectra of the Fe $2 p$ area of (left) free $\beta$-diketones $\mathrm{FcCOCH}_{2} \mathrm{COR}$, 2a-2e, and of (middle) the Fe $2 p$ area of $\left[\mathrm{Mn}(\mathrm{FcCOCHCOR})_{3}\right]$ complexes 3a-3d and (right) of the $\mathrm{Mn} 2 \mathrm{p}$ area of $\mathbf{3 a}-\mathbf{3 d}$. The figure on the right also shows the XPS for $\left[\mathrm{Mn}\left(\mathrm{H}_{3} \mathrm{CCOCHCOCH}_{3}\right)_{3}\right]$; it is labeled "acac". The red dotted lines (web version of the article) are exactly vertical whereas the black dotted lines follow measured BE values. (CPS $=$ counts per second.)

The only other photoelectron lines which could be detected in the XPS of $\mathbf{2 b}, \mathbf{2 c}$ and $\mathbf{2 d}$ were carbon (ca. $284.8 \mathrm{eV}$ ) and oxygen (ca. $528.8 \mathrm{eV}$ ). $\beta$-Diketones $\mathbf{2 a}, \mathrm{FcCOCH}_{2} \mathrm{COCF}_{3}$, and $\mathbf{2 e}$, $\mathrm{FcCOCH}_{2} \mathrm{COC}_{6} \mathrm{~F}_{5}$, also showed fluorine at ca. $688.2 \mathrm{eV}$ and $688.1 \mathrm{eV}$ respectively. Within experimental error (2-4\%), the correct ratio between the F 1s peak and the Fe $2 \mathrm{p}$ peaks of $\mathbf{2 a}$ (correct ratio is 3:1) and $\mathbf{2 e}$ (correct ratio is 5:1) were obtained; 2.9:1 and 4.9:1 respectively. 


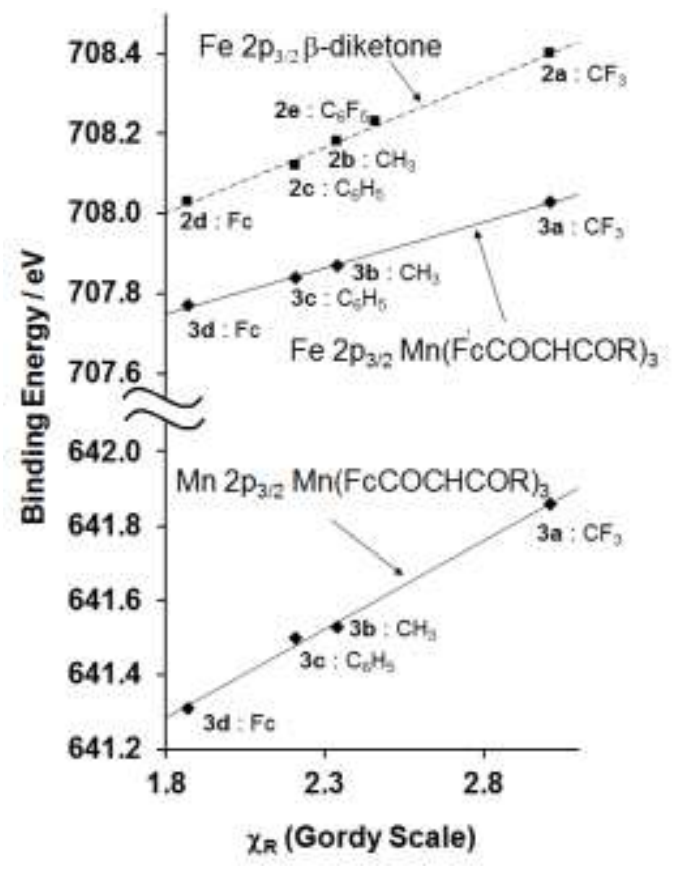

Figure 4. Relationship between binding energy of the $\mathrm{Fe} 2 \mathrm{p}_{3 / 2}$ photoelectron line and Gordy scale group electronegativities, $\chi_{\mathrm{R}}$, of the R-groups on $\mathrm{FcCOCH}_{2} \mathrm{COR} \beta$-diketones $\mathbf{2 a - 2 e}$ (top, ----), and [Mn(FcCOCHCOR$)_{3}$ ] complexes 3a-3d (middle, $\longrightarrow$ ), and the Mn 2 $\mathrm{p}_{3 / 2}$ photoelectron line (bottom).

Table 3: The Gordy group electronegativity, $\chi_{R}$, of the various R-groups on $\beta$-diketones $\left(\mathrm{FcCOCH}_{2} \mathrm{COR}, \mathbf{2 a}-2 \mathrm{e}\right)$, the binding energies (BE) of the fitted $\mathrm{Fe} 2 \mathrm{p}_{3 / 2}$ and $\mathrm{F} 1 \mathrm{~s}$ peaks of the $\beta$ diketones, the $\mathrm{Fe} 2 \mathrm{p}_{3 / 2}, \mathrm{Mn} 2 \mathrm{p}_{3 / 2}$ and $\mathrm{F} 1$ s peaks of $\left[\mathrm{Mn}(\mathrm{FcCOCHCOR})_{3}\right]$ complexes $\mathbf{3 a}-\mathbf{3 d}$, $\left[\mathrm{Mn}(\mathrm{FcCOCHCOFc})_{2}\left(\mathrm{FcCOCHCOCH}_{3}\right)\right], \mathbf{4}$, and $\left[\mathrm{Mn}\left(\mathrm{H}_{3} \mathrm{CCOCHCOCH}_{3}\right)_{3}\right]$ as well as the ratio between $\mathrm{Mn}, \mathrm{Fe}$ and F.

\begin{tabular}{|c|c|c|c|c|c|c|}
\hline Comp.: R & $\chi_{R}{ }^{a}$ & $\begin{array}{c}\text { Fe } 2 p_{3 / 2} \mathrm{BE} \text { of } \\
\beta \text {-diketones } \\
/ \mathrm{eV}\end{array}$ & $\begin{array}{c}\mathrm{Fe} 2 \mathrm{p}_{3 / 2} \mathrm{BE} \text { of } \\
\text { Mn complexes } \\
/ \mathrm{eV}\end{array}$ & $\begin{array}{c}\text { Mn } 2 p_{3 / 2} \text { BE of } \\
\text { Mn complexes } \\
/ \text { eV }\end{array}$ & $\begin{array}{c}\text { Measured } \\
\text { Mn:Fe:F } \\
\text { Ratio }\end{array}$ & $(\mathrm{Chi})^{2}$ of fit \\
\hline 2a, $\mathbf{3 a}: \mathrm{CF}_{3}$ & 3.01 & $708.40 ; 688.19^{b}$ & $708.03 ; 687.94^{b}$ & 641.86 & $1: 3.2: 9.4$ & $1.68^{\mathrm{e}} ; 1.24^{\mathrm{f}} ; 1.06^{\mathrm{g}}$ \\
\hline 2e: $\mathrm{C}_{6} \mathrm{~F}_{5}$ & 2.46 & $708.23 ; 688.09^{b}$ & - & - & - & $1.37^{\mathrm{e}}$ \\
\hline $\mathbf{2 b}, \mathbf{3 b}: \mathrm{CH}_{3}$ & 2.34 & 708.18 & 707.87 & 641.53 & $1: 3.2$ & $1.04^{\mathrm{e}} ; 1.13^{\mathrm{f}} ; 2.52^{\mathrm{g}}$ \\
\hline 2c:, 3c: $\mathrm{C}_{6} \mathrm{H}_{5}$ & 2.21 & 708.12 & 707.84 & 641.50 & $1: 2.9$ & $1.46^{\mathrm{e}} ; 1.11^{\mathrm{f}} ; 2.10^{\mathrm{g}}$ \\
\hline 2d, 3d: $\mathrm{Fc}$ & 1.87 & 708.03 & 707.77 & 641.31 & $1: 6$ & $1.81^{\mathrm{e}} ; 1.28^{\mathrm{f}} ; 1.38^{\mathrm{g}}$ \\
\hline 4: $\mathrm{Fc}, \mathrm{Fc}, \mathrm{CH}_{3}{ }^{\mathrm{c}}$ & - & - & 707.79 & 641.41 & $1: 5$ & $0.97^{\mathrm{f}} ; 2.38^{\mathrm{g}}$ \\
\hline $\mathrm{acac}^{\mathrm{d}}$ & - & - & - & 641.73 & - & $0.88^{\mathrm{g}}$ \\
\hline
\end{tabular}

${ }^{a}$ Values from reference $32 .{ }^{b}$ Binding energy of the $\mathrm{F} 1 \mathrm{~s} \mathrm{peak}$ in $\mathrm{eV} .{ }^{\mathrm{c}}$ This R-group combination gives rise to the complex $\left.\left[\mathrm{Mn}(\mathrm{FcCOCHCOFc})_{2}(\mathrm{FcCOCHCOCH})_{3}\right)\right], 4{ }^{\mathrm{d}}{ }^{2}$ The complex $\left[\mathrm{Mn}\left(\mathrm{CH}_{3} \mathrm{COCHCOCH}_{3}\right)_{3}\right]$ is abbreviated "acac". ${ }^{\mathrm{e}}(\mathrm{Chi})^{2}$ fit of the Fe $2 \mathrm{p}$ peaks of the b-diketone. ${ }^{\mathrm{f}}(\mathrm{Chi})^{2}$ fit of the Fe $2 \mathrm{p}$ peaks of the Mn-complex. ${ }^{\mathrm{g}}(\mathrm{Chi})^{2}$ fit of the $\mathrm{Mn} 2 \mathrm{p}$ peaks of the Mn-complex. Note: The goodness-of-fit parameter, $(\mathrm{Chi})^{2}$, must not be confused with $\chi$, which is the official symbol of group electronegativities and is used throughout this manuscript. 
It is evident that as the Gordy group electronegativity, ${ }^{19} \chi_{R}$, of the R group on the $\beta$-diketonato ligand increases the binding energy of the iron, Fe 2p peaks, also increases (see Fig.'s 3 and 4 and the result summary in Table 3). This is due to an increased ionic bond character on the iron because more electron density is moving away from the $\mathrm{Fe}^{2+}$ ion towards stronger electronwithdrawing substituents. This causes the $\mathrm{Fe}^{2+}$ ions to bind more tightly to their own electrons leading to increased binding energy values. The linear relationship obtained between the binding energy (BE) of the $\beta$-diketone iron Fe $2 \mathrm{p}_{3 / 2}$ peaks and $\chi_{\mathrm{R}}$ (Fig. 4) fits the equation

$$
B E=0.3306 \chi_{R}+707.41 ; R^{2}=0.9944
$$

The manganese(III) complexes of these ferrocenyl-containing $\beta$-diketones, complexes 3a-3d, exhibited the same spectral features as the $\beta$-diketones and additionally also Mn $2 \mathrm{p}$ peaks. The ratio between the Mn 2p peaks and the Fe 2p peaks are as expected for each compound (Table 3). The Mn(III) center within complexes $\mathbf{3 a}-\mathbf{3 d}$ is in a high spin state. ${ }^{39}$ This induces the formation of multiplet splitting, ${ }^{40}$ which in turn causes the peaks of both the Mn $2 \mathrm{p}$ and the Fe $2 \mathrm{p}$ (of the ligand) to have a broader than expected FWHM.

Compared to the free $\beta$-diketones, $\mathbf{2 a - 2 d}$, the Fe $2 p$ peaks of complexes $\mathbf{3 a}-\mathbf{3 d}$ are still welldefined peaks and only one Gaussian peak fit was necessary for all of them. However, peak fitting required a FWHM of ca. $2.7 \mathrm{eV}$. This is ca. $1 \mathrm{eV}$ more than for the free $\beta$-diketone ligands. This 1 eV larger FWHM can be attributed to a combination of the high spin state of the Mn(III) metal center as well as the known fact that the octahedral Mn(III) complexes exists in both fac and mer conformations (see subscript Scheme 1) which indicates that the chemical environment of all the different ferrocenyl groups in these different conformations are not the same. 
As was found for the free $\beta$-diketonato ligands, an increase in ligand $R$-group $\chi_{R}$ is accompanied by an increase in the binding energy of the iron Fe 2p peaks (Fig.'s 3 and 4, Table 3 ) in $\left[\mathrm{Mn}(\mathrm{FcCOCHCOR})_{3}\right]$ complexes. The binding energy of the $\mathrm{Fe}^{2+} 2 \mathrm{p}_{3 / 2}$ peaks is found in the range $707.77-708.03 \mathrm{eV}$; this is a $0.28 \mathrm{eV}$ span. They are ca. $0.3 \mathrm{eV}$ lower in energy than in the free ligands. This move to lower binding energies highlights the chemical influence of $\mathrm{Mn}^{3+}$ coordination to $(\mathrm{FcCOCHCOR})^{-}$ligands and implies that the electron-withdrawing ability of $\mathrm{H}^{+}$is more than that of $1 / 3 \mathrm{Mn}^{3+}$. XPS Mn 2 $\mathrm{p}_{3 / 2}$ signals were found (Table 3) in the range 641.86-641.31 eV (a range of $0.55 \mathrm{eV}$ ) with spin orbit splitting between the Mn 2 $\mathrm{p}_{3 / 2}$ and $\mathrm{Mn} 2 \mathrm{p}_{1 / 2}$ levels of $11.7 \mathrm{eV}$. The binding energy range of $0.55 \mathrm{eV}$ is unusually large as a full redox state change from $\mathrm{Mn}^{2+}$ to $\mathrm{Mn}^{3+}$ would normally be accompanied by a change in binding energy of $1 \mathrm{eV}$. The Mn 2p peaks were charge corrected against $\mathrm{C} 1 \mathrm{~s}$ at $284.8 \mathrm{eV}$ (the lowest binding energy of the fitted adventitious $\mathrm{C} 1 \mathrm{~s}$ peak). A FWHM of ca. $3.1 \mathrm{eV}$ was used in curve fittings. This broadening in FWHM compared to what was found for Fe can again be attributed to a combination of the high spin state of the Mn(III) metal center as well as the presence of $f a c$ and mer conformations in the bulk [ $\left.\mathrm{Mn}(\mathrm{FcCOCHCOR})_{3}\right]$ material. The position of the binding energy of the $\mathrm{Mn} 2 \mathrm{p}_{3 / 2}$ peaks at ca. $641 \mathrm{eV}$ is comparable to those found for $\mathrm{Mn}_{0.25} \mathrm{Fe}_{0.75} \mathrm{Cr}_{2} \mathrm{O}_{4}(640.8 \mathrm{eV})^{41}$ and $\left[\mathrm{Mn}(\mathrm{CO}){ }_{3}\left(\mathrm{C}_{5} \mathrm{H}_{5}\right)\right](640.6 \mathrm{eV}) .{ }^{36}$ Similar to the Fe 2p peaks, the binding energy of the Mn $2 p$ peaks also increases with increase in R-group $\chi_{R}$ (Fig.'s 3 and 4, Table 3).

The linear relationship obtained between the binding energy (BE) of the iron $\mathrm{Fe} 2 \mathrm{p}_{3 / 2}$ peaks as well as the $\mathrm{Mn} 2 \mathrm{p}_{3 / 2}$ peaks and $\chi_{\mathrm{R}}$ for $\left[\mathrm{Mn}(\mathrm{FcCOCHCOR})_{3}\right]$ complexes is described by equations 2 and 3. 
Fe $2 \mathrm{p}_{3 / 2}$ peaks:

$B E=0.2299 \chi_{R}+707.34 ; R^{2}=0.9986$

Mn 2p $\mathrm{p}_{3 / 2}$ peaks:

$B E=0.4770 \chi_{R}+640.43 ; R^{2}=0.9961$

The accuracy of equations 1 and 2 (i.e. of data points) is underlined by the Y-intercept values which are 707.41 and 707.34 respectively. These values, almost 1.9 group electronegativity units away from the lowest $\chi_{\mathrm{Fc}}=1.87$ value could not be so close to each other if the data points were not of high quality.

To expand Equation 3 to also include $\beta$-diketonato complexes that do not contain the ferrocenyl group in the ligand, evaluation of the XPS results of $\left[\mathrm{Mn}\left(\mathrm{CH}_{3} \mathrm{COCHCOCH}_{3}\right)_{3}\right]$ and $\left[\mathrm{Mn}(\mathrm{FcCOCHCOFc})_{2}\left(\mathrm{FcCOCHCOCH}_{3}\right)\right], 4$, is beneficial and the concept $\Sigma \chi_{\mathrm{R}}$, which is the sum of all $\beta$-diketonato R-group electronegativities, required. The binding energy of the $\mathrm{Mn} 2 \mathrm{p}_{3 / 2}$ peak of the $\left[\mathrm{Mn}\left(\mathrm{CH}_{3} \mathrm{COCHCOCH}_{3}\right)_{3}\right]$ complex is found at $641.73 \mathrm{eV}$, ca. $0.2 \mathrm{eV}$ larger than for the $\left[\mathrm{Mn}\left(\mathrm{FcCOCHCOCH}_{3}\right)_{3}\right]$ complex (Table 3). This again highlights that the electron-donating properties of the ferrocenyl group are stronger than those of methyl group. By way of demonstrating the calculation of $\Sigma \chi_{\mathrm{R}}, \Sigma \chi_{\mathrm{R}}$ for $\left[\mathrm{Mn}(\mathrm{FcCOCHCOFc})_{2}\left(\mathrm{FcCOCHCOCH}_{3}\right)\right]$, 4, would be $\Sigma \chi_{\mathrm{R}, 4}=5 \chi_{\mathrm{Fc}}+\chi_{\mathrm{CH} 3}=5(1.87)+2.34=11.69$. Similarly, $\Sigma \chi_{\mathrm{R},[\mathrm{Mn}(\mathrm{CH} 3 \mathrm{COCHCOCH} 3) 3]_{3}}=6\left(\chi_{\mathrm{CH} 3}\right)=$ 14.04 .

The XPS spectra of the mixed $\beta$-diketonato Mn(III) complex, $\mathbf{4}$, showed a Mn:Fe ratio of 1:5. This ratio confirms that there are two bis-ferrocenyl $\beta$-diketonato ligands and one mono-ferrocenyl $\beta$ diketonato ligand coordinated to $\mathrm{Mn}(\mathrm{III})$. The positions of the $\mathrm{Fe} 2 \mathrm{p}_{3 / 2}$ and $\mathrm{Mn} 2 \mathrm{p}_{3 / 2}$ signals were found at $707.79 \mathrm{eV}$ and $641.41 \mathrm{eV}$ respectively. This $0.1 \mathrm{eV}$ move of $\mathrm{Mn} 2 \mathrm{p}_{3 / 2}$ binding energy to a 
larger value compared to that of $\mathbf{3 d}$, $\left.\left[\mathrm{Mn}(\mathrm{FcCOCHCOFc})_{3}\right]\right),(641.31 \mathrm{eV})$ is consistent with replacement of one electron-donating ferrocenyl group with one less electron-donating methyl group, Table 3 .

To be capable to predict binding energies for all manganese(III) $\beta$-diketonato complexes irrespective of the presence or absence of a ferrocenyl group in the $\beta$-diketonato ligand, a linear relationship must exist between $\Sigma \chi_{R}$ and Mn binding energies for all complexes. This relationship is shown in Fig. 5 and satisfies the equation

\section{$B E=0.1517 \Sigma \chi_{R}+639.62 ; R^{2}=0.9919$}

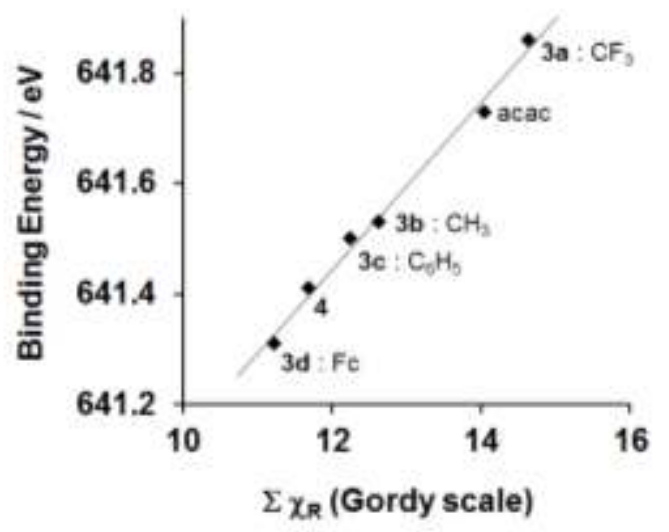

Figure 5. Relationship between binding energy of the $\mathrm{Mn} 2 \mathrm{p}_{3 / 2}$ photoelectron line and the sum of $\beta$-diketonato ligand Gordy scale R-group electronegativities, $\Sigma \chi_{R}$, of $\left[\mathrm{Mn}\left(\mathrm{FcCOCHCOR}_{3}\right]\right.$ complexes 3a-3d, the "acac" complex $\left[\mathrm{Mn}\left(\mathrm{H}_{3} \mathrm{CCOCHCOCH}_{3}\right)_{3}\right]$ and $\left[\mathrm{Mn}(\mathrm{FcCOCHCOFc})_{2}\left(\mathrm{FcCOCHCOCH}_{3}\right)\right], 4$.

Once again, Mn 2 $\mathrm{p}_{3 / 2} \mathrm{BE}$ data point quality are very good as demonstrated by $\mathrm{Y}$-interceptions values which are close to each other in equations 3 and 4 (640.43 and $639.62 \mathrm{eV}$ respectively). These values are placed in perspective upon recognizing that the lowest experimental BE value in 
equation 3 is 1.87 group electronegativity units away from the $\mathrm{Y}$-axis, but for equation 4, it is a full 11.22 group electronegativity units away from the smallest data point belonging to $\Sigma \chi_{R}$ of $\mathbf{3 d}$. The linearity of the relationships between $\chi_{R}$ and $\Sigma \chi_{R}$ and the binding energies of the Fe $2 p_{3 / 2}$ photoelectron line and the $\mathrm{Mn} 2 \mathrm{p}_{3 / 2}$ photoelectron line confirms the crystallographic predicted capability of $\left[\mathrm{Mn}(\mathrm{FcCOCHCOR})_{3}\right]$ complexes to transmit electronic effects from one molecular fragment to another. Moreover, it allows prediction of binding energies of these classes of compounds with equations 1-4 provided the group electronegativity of $\beta$-diketonato R-group substituents are known.

\section{Conclusions}

Three novel complexes of the type $\left[\mathrm{Mn}(\mathrm{FcCOCHCOR})_{3}\right]$ with $\mathrm{R}=\mathrm{CF}_{3}, \mathrm{Ph}$ and $\mathrm{Fc}$ as well as the new mixed ligand complex $\left[\mathrm{Mn}(\mathrm{FcCOCHCOFc})_{2}(\mathrm{FcCOCHCOCH} 3)\right]$ and the known complex $\left[\mathrm{Mn}\left(\mathrm{FcCOCHCOCH}_{3}\right)_{3}\right]$ were found to be easily available in moderate yields $(30-60 \%)$ from a newly developed synthetic route towards ferrocene-containing manganese(III) complexes. Bond lengths and bond angles of the single crystal X-ray structure determination of the fac isomer of $\left[\mathrm{Mn}\left(\mathrm{FcCOCHCOCH}_{3}\right)_{3}\right]$ suggested that intramolecular communication between molecular fragments of these manganese complexes is likely to be detected by suitable techniques. An X-ray

photoelectron spectroscopic (XPS) study showed that this is indeed the case. Utilizing the Fe $2 \mathrm{p}_{3 / 2}$ photoelectron peak of the ferrous $\mathrm{Fe}^{2+}$ ions of the ferrocenyl moiety of the free $\beta$-diketone precursors as well as the manganese ferrocene-containing $\beta$-diketonato complexes, and also the Mn $2 \mathrm{p}_{3 / 2}$ photoelectron peaks, a linear relationship was found between Fe (and $\mathrm{Mn}$ ) binding energies and R-group group electronegativities, $\chi_{\mathrm{R}}$ as well as $\Sigma \chi_{\mathrm{R}}$. No such relationship has ever 
before been demonstrated. The range of binding energy changes in moving from $\mathrm{R}=\mathrm{CF}_{3}\left(\chi_{\mathrm{CF} 3}=\right.$ 3.01) to $\mathrm{R}=\mathrm{Fc}\left(\chi_{\mathrm{Fc}}=1.87\right)$ spanned $0.37 \mathrm{eV}$ for the Fe peaks of the free betadiketones, $0.26 \mathrm{eV}$ for the Fe peaks of the Mn complexes, and an extraordinarily large $0.55 \mathrm{eV}$ for the Mn centre of the Mn complexes. This large binding energy domain is placed in perspective by recognizing that a full one-electron redox state change (e.g. from $\mathrm{Fe}^{2+}$ to $\mathrm{Fe}^{3+}$, or $\mathrm{Mn}^{2+}$ to $\mathrm{Mn}^{3+}$ ) normally represents a binding energy change of $1 \mathrm{eV}$. It also follows from this unique result that binding energies from similar complexes may now be empirically predicted from a knowledge of $\beta$-diketonato side group $\chi_{R}$ values if such group electronegativities are known.

\section{Experimental Section}

\subsection{General}

Solid reagents (ferrocene, $\left[\mathrm{Mn}_{3}(\mathrm{OAc})_{6} \mathrm{O} .3 \mathrm{H}_{2} \mathrm{O}\right][\mathrm{OAc}](\mathbf{1})$, marketed as $\left[\mathrm{Mn}\left(\mathrm{CH}_{3} \mathrm{COO}\right)_{3}\right] \cdot 2 \mathrm{H}_{2} \mathrm{O}$, $\mathrm{MnCl}_{2} \cdot 4 \mathrm{H}_{2} \mathrm{O}, \mathrm{KMnO}_{4}$ from Aldrich and $\mathrm{CH}_{3} \mathrm{COONa}$ from Saarchem) were used without any further purification. Dichloromethane was dried by distillation from calcium hydride and, to remove photochemically generated $\mathrm{HCl}$, passed through basic alumina prior to use. Doubly distilled water was used throughout. Ferrocene-containing $\beta$-diketones $\mathrm{FcCOCH}_{2} \mathrm{COR}$ with $\mathrm{R}=$ $\mathrm{CH}_{3}(\mathbf{2 a}), \mathrm{CF}_{3}(\mathbf{2 b}), \mathrm{Ph}(\mathbf{2 c}), \mathrm{Fc},(\mathbf{2 d})$ and $\mathrm{C}_{6} \mathrm{~F}_{5}$, were synthesized utilizing published procedures ${ }^{32}$ with care being taken to separate it from the aldol self-condensation product of acetyl ferrocene, $\mathrm{FcCOCH}=\mathrm{C}\left(\mathrm{CH}_{3}\right) \mathrm{Fc}^{42}{ }^{42}$ Tris(acetylacetonato) manganese(III ${ }^{43}$ was prepared as described before. Column chromatography was performed on Kieselgel 60 (Merck, grain size 0.040-0.063 nm) using hexane:diethyl ether (1:1) as mobile phase unless otherwise specified. 
Infrared spectra of neat samples were recorded with a Thermo Scientific IR spectrometer and NICOLET iS50 ATR attachment, running OMNIC software (Version 9.2.86). UV-Vis spectra were recorded on a Cary 5000 Probe UV-Vis-NIR spectrophotometer utilizing dichloromethane as solvent and a $1 \mathrm{~cm}$ path length quartz cuvette. Given that $\mathrm{Mn}(\mathrm{III})$ is paramagnetic, no NMR data of the manganese complexes $\mathbf{3 a}-\mathbf{3 d}$ and $\mathbf{4}$ are reported. Melting points were determined using analytically pure samples on an Olympus BX51 microscope, using a LINKAM, TMS 600 hot stage. Elemental analyses were performed by Canadian Microanalytical Service, Delta, British Columbia, Canada.

\subsection{Synthesis of complexes $\mathbf{3 a - 3 d}$ and $\mathbf{4}$.}

Complex $\mathbf{3 b}$ was prepared according to both methods A and B while complexes $\mathbf{3 a}, \mathbf{3 c}-\mathbf{3 d}$ and $\mathbf{4}$ were prepared following method B only; 3b may serve as an example.

Method A: Following an adaption of Zanello's method, ${ }^{11}$ to an aqueous solution $\left(10 \mathrm{~cm}^{3}\right)$ of $\mathrm{MnCl}_{2} \cdot{ }_{4} \mathrm{H}_{2} \mathrm{O}(0.039 \mathrm{~g}, 0.20 \mathrm{mmol})$ and $\mathrm{NaOAc}(0.057 \mathrm{~g}, 0.70 \mathrm{mmol})$ was added a solution of $2 \mathbf{b}$ $(0.20 \mathrm{~g}, 0.74 \mathrm{mmol})$ in $\mathrm{CH}_{3} \mathrm{CN}\left(10 \mathrm{~cm}^{3}\right)$. After stirring for 10 minutes a solution of $\mathrm{KMnO}_{4}(7.81$ $\mathrm{mg}, 0.049 \mathrm{mmol})$ in water $\left(2 \mathrm{~cm}^{3}\right)$ was added drop-wise to the mixture and stirred for another 10 minutes. Another aqueous solution $\left(10 \mathrm{~cm}^{3}\right)$ of $\mathrm{NaOAc}_{3} 3 \mathrm{H}_{2} \mathrm{O}(0.057 \mathrm{~g}, 0.70 \mathrm{mmol})$ was added and the reaction mixture was heated to $60{ }^{\circ} \mathrm{C}$ for 10 minutes. The deep red-brown precipitate was filtered after cooling to room temperature. Washing the precipitate with copious amounts of water and then with methanol yielded $150 \mathrm{mg}(70 \%)$ of complex $\mathbf{3 b}$. The complex could be crystallized from slowly evaporating toluene.

General procedure method B: To a solution of $\mathbf{2 b}(0.50 \mathrm{~g}, 1.85 \mathrm{mmol})$ in acetone $\left(75 \mathrm{~cm}^{3}\right)$ was added an aqueous solution $\left(20 \mathrm{~cm}^{3}\right)$ of $\left[\mathrm{Mn}_{3}(\mathrm{OAc})_{6} \mathrm{O} .3 \mathrm{H}_{2} \mathrm{O}\right][\mathrm{OAc}](0.165 \mathrm{~g}, 0.62 \mathrm{mmol})$ while stirring vigorously. After drop-wise adding a solution of $\mathrm{NaOAc}(0.152 \mathrm{~g} ; 1.85 \mathrm{mmol})$ in water (5 
$\mathrm{cm}^{3}$ ), the reaction mixture was allowed to stir at ambient conditions for 16 hours. The resulting precipitate was filtered off and washed firstly with plenty of water and then with methanol $\left(2 \mathrm{~cm}^{3}\right)$. Drying at reduced pressure yielded $370 \mathrm{mg}(57 \%)$ based on $\left[\mathrm{Mn}_{3}(\mathrm{OAc})_{6} \mathrm{O} .3 \mathrm{H}_{2} \mathrm{O}\right][\mathrm{OAc}]$ of complex 3b. Small crystallographic quality needle-like crystals of $\mathbf{3 b}$ were obtained from slow evaporation of a toluene solution of the complex.

\section{Characterization data}

Complex 3a. Yield: $210 \mathrm{mg}\left(0.21 \mathrm{mmol}, 33 \%\right.$ based on $\left.\left[\mathrm{Mn}_{3}(\mathrm{OAc})_{6} \mathrm{O} .3 \mathrm{H}_{2} \mathrm{O}\right][\mathrm{OAc}]\right)$. Elemental analysis: Calc. for $\mathrm{C}_{42} \mathrm{H}_{30} \mathrm{~F}_{9} \mathrm{Fe}_{3} \mathrm{MnO}_{6} \mathrm{C}$, 49.3; H, 3.0; Fe, 16.4; Mn, 5.4\%. Found: C, 49.6; H, 3.0; Fe, 17.2; Mn, 4.7\%. M.p. $>250{ }^{\circ} \mathrm{C}(\mathrm{dec})$. IR (NaCl): v/cm ${ }^{-1}: 1572$ (vs),1535 (s).

Complex 3b, method B, Yield: $370 \mathrm{mg}\left(0.43 \mathrm{mmol}, 57 \%\right.$ based on [ $\left.\mathrm{Mn}_{3}(\mathrm{OAc})_{6} \mathrm{O} .3 \mathrm{H}_{2} \mathrm{O}\right][\mathrm{OAc}]$. The crystal structure showed one solvent (toluene) molecule to be trapped in the crystals. Elemental analysis, utilizing the molecular mass as determined by the crystal structure determination: Calc. for $\mathrm{C}_{45.29} \mathrm{H}_{42.29} \mathrm{Fe}_{3} \mathrm{MnO}_{6} \mathrm{C}, 60.1 ; \mathrm{H}, 4.7$; Fe, 18.5; Mn, 6.1\%. Found: C, 59.8; H, 4.7; Fe, 19.0; Mn, 5.5\%. M.p. >250 ${ }^{\circ} \mathrm{C}$ (dec). IR (NaCl): v/ $\mathrm{cm}^{-1}: 1542$ (vs), 1506 (m). Complex 3c. Yield: $465 \mathrm{mg}\left(0.44 \mathrm{mmol}, 70 \%\right.$ based on $\left.\left[\mathrm{Mn}_{3}(\mathrm{OAc})_{6} \mathrm{O} .3 \mathrm{H}_{2} \mathrm{O}\right][\mathrm{OAc}]\right)$. Elemental analysis: Calc. for $\mathrm{C}_{57} \mathrm{H}_{45} \mathrm{Fe}_{3} \mathrm{MnO}_{6} \mathrm{C}, 65.3 ; \mathrm{H}, 4.3$; Fe, 16.0; Mn, 5.2\%. Found: C, 65.5; H, 4.5; Fe, 16.4; Mn, 4.7\%. M.p. $>250{ }^{\circ} \mathrm{C}$. IR (NaCl): v/cm ${ }^{-1}: 1506$ (vs), 1483 (s). Complex 3d. Yield: $245 \mathrm{mg}\left(0.18 \mathrm{mmol}, 49 \%\right.$ based on $\left.\left[\mathrm{Mn}_{3}(\mathrm{OAc})_{6} \mathrm{O} .3 \mathrm{H}_{2} \mathrm{O}\right][\mathrm{OAc}]\right)$. Elemental analysis: Calcd. for $\mathrm{C}_{69} \mathrm{H}_{57} \mathrm{Fe}_{6} \mathrm{MnO}_{6} \mathrm{C}, 60.4 ; \mathrm{H}, 4.2 ; \mathrm{Fe}, 21.4 ; \mathrm{Mn}, 4.0 \%$. Found: C, 59.5; H, 4.1; Fe, 21.2; Mn, 4.6\%. M.p. $>250{ }^{\circ} \mathrm{C}$ (dec.). IR (NaCl): v/ $\mathrm{cm}^{-1}: 1501$ (vs), 1457 (m).

Complex 4. Yield: $105 \mathrm{mg}\left(0.47 \mathrm{mmol}, 44 \%\right.$ based on $\left.\left[\mathrm{Mn}_{3}(\mathrm{OAc}) \mathrm{O} .3 \mathrm{H}_{2} \mathrm{O}\right][\mathrm{OAc}]\right)$. Elemental analysis: Calcd. for $\mathrm{C}_{60} \mathrm{H}_{51} \mathrm{Fe}_{5} \mathrm{MnO}_{6} \mathrm{C}, 59.9 ; \mathrm{H}, 4.3$; Fe, 23.2; Mn, 4.6\%. Found: C, 60.7; H, 4.4; Fe, 23.1; Mn, 4.5\%. M.p. $>250{ }^{\circ} \mathrm{C}$ (dec.). IR (NaCl): v/ $\mathrm{cm}^{-1}: 1498$ (vs), 1456 (m). 


\subsection{Crystal structure determination of $\mathbf{3 b}$}

Data for complex 3b was collected at $150 \mathrm{~K}$ on a Bruker D8 Venture kappa geometry diffractometer, with duo I $\mu$ s sources, a Photon 100 CMOS detector and APEX II control software using Quazar multi-layer optics, monochromated Mo-K $\alpha$ radiation and by means of a combination of $\phi$ and $\omega$ scans. Data reduction was performed using SAINT+ and the intensities were corrected for absorption using SADABS.$^{44}$ The structure was solved by intrinsic phasing using SHELXTS and refined by full-matrix least squares using SHELXTL and SHELXL-2013. ${ }^{45}$ In the structure refinement, all hydrogen atoms were added in calculated positions and treated as riding on the atom to which they are attached. All nonhydrogen atoms were refined with anisotropic displacement parameters. All isotropic displacement parameters for hydrogen atoms were calculated as $\mathrm{X} \times$ Ueq of the atom to which they are attached, $\mathrm{X}=1.5$ for the methyl hydrogens and 1.2 for all other hydrogens. The structure includes a disordered molecule of toluene that includes an inversion centre. The site occupancy of the atoms of the solvent molecule refined to a value of 0.9414. Crystallographic data and refinement parameters are given in Table 1. An Ortep drawing ${ }^{46}$ of the structure is included in Figure 2. The crystal structure (cif) has been deposited at the Cambridge Crystallographic Data Centre and allocated the deposition number CCDC 1421438. Data collection, structure solution and refinement details are available in the cif.

\section{$4.4 \quad X$-ray photoelectron spectroscopy}

XPS data were recorded on a PHI 5000 Versaprobe system with monochromatic AlKa X-ray source. Powered samples were mounted on the sample holder by means of carbon tape. Spectra were obtained using the aluminium anode $(\mathrm{Al} \mathrm{K \alpha}=1486.6 \mathrm{eV})$ operating at $50 \mu \mathrm{m}, 12.5 \mathrm{~W}$ and 15 $\mathrm{kV}$ energy. The survey scans were recorded at constant pass energy of $187.85 \mathrm{eV}$ and region scans 
at constant pass energy of $29.35 \mathrm{eV}$, with an energy step of $0.1 \mathrm{eV}$; the analyzer resolution is $\leq 0.5$ $\mathrm{eV}$. Charge neutralisation was enhanced by shooting the mounted sample with an Ar gun during data recording. The background pressure was $2 \times 10^{-8}$ mbar. The XPS data were analyzed utilizing Multipak version $8.2 \mathrm{c}$ computer software ${ }^{35}$ using Gaussian-Lorentz fits (the Gaussian/Lorentz ratios were always $>95 \%$ ). The photoelectron lines were charge corrected against the lowest binding energy of the fitted adventitious $\mathrm{C} 1 \mathrm{~s}$ peak at $284.8 \mathrm{eV}$ (the normal position of C-C according to the XPS Handbook ${ }^{35}$ ). The carbon peak of all the complexes were fitted to 3 peaks, namely $\mathrm{C}-\mathrm{C}$ at $284.8 \mathrm{eV}, \mathrm{C}=\mathrm{C}$ at $285.5 \mathrm{eV}$ and $\mathrm{C}=\mathrm{O}$ at $286.7 \mathrm{eV}$.

\section{Acknowledgements}

JCS acknowledges the NRF under grant 2054243 and the UFS for financial support. Financial support from Syngaschem BV, The Netherlands, and the UFS is also gratefully acknowledged (BEB, EE, JCS).

\section{Notes}

The authors declare no competing financial interest.

Supporting Information. Wide scans and other XPS spectra of compounds, as well as crystallographic data for $\mathbf{3 b}$. The cif file of $\mathbf{3 b}$ contains all the supplementary crystallographic data for this paper. This material is available free of charge via the Internet at http://pubs.acs.org or from the Cambridge Crystallographic Data Centre, 12, Union Road, Cambridge CB2 1EZ, UK; fax: +44 1223 336033, CCDC 1421438, http://www.ccdc.cam.ac.uk/conts/retrieving.html). 


\section{References.}

1 (a) Geiger, W. E. Coord. Chem. Rev. 2013, 257, 1459. (b) Wu, K.; Laws, D. R.; Nafady, Y.; Geiger W. E. J. Inorg. Organomet.Pol. Mat. 2014, 24, 137.

2 Cotton, F. A.; Wilkinson, G.; Murillo, C. A.; Bochmann, M. Advanced Inorganic Chemistry; 6th Ed., Wiley and Sons, New York, 1999.

3 (a) Van Gorkum, R.; Bouwman, E.; Reedijk, J. Inorg. Chem., 2004, 43, 2456. (b) Oyman, Z. O.; Ming, W.; Van der Linde, R.; Van Gorkum, R.; Bouwman, E. Polymer, 2005, 46, 1731.

4 (a) Tembe, G. L.; Ganeshpure, P. A.; Satish, S. React. Kinet. Catal. Lett., 1998, 63, 385. (b) González, L. M.; Villa de P., A. L.; Montes de C., C.; Sorokin, A. Tetrahedron Lett., 2006, 47, 6465. (c) Katsuki, T. Coord. Chem. Rev., 1995, 140, 189.

5 (a) Bernard, A. S.; Giroud, C.; Vincent Ching, H. Y.; Meunier, A.; Ambike, V.; Amatore, C.; Collignon, M. G.; Lemaîtrea, F.; Policar, C. Dalton Trans., 2012, 41, 6399. (b) Iranzo, O. Bioorg. Chem., 2011, 39, 73. (c) Barnese, K.; Gralla, E. B.; Cabelli, D. E.; Valentine, J. S. J. Am. Chem. Soc., 2008, 130, 4604. (d) Gorkum, R. V.; Berding, J.; Tooke, D. M.; Spek, A. L.; Reedijk, J.; Bouwman, E. J. Catal., 2007, 252, 110.

6 (a) Aromi, G.; Brechin, E. K. Struct. Bonding, 2006, 122, 1. (b) Langley, S. K.; Chilton, N. F.; Massi, M.; Moubaraki, B.; Berry, K. J.; Murray, K. S. Dalton Trans., 2010, 39, 7236. (c) Winpenny, R. E. P. Comp. Coord. Chem. II, 2004, 7, 125.

7 Barra, A. L.; Gatteschi, D.; Sessoli, R.; Abbati, G. L.; Cornia, A.; Fabretti, A. C.; Uytterhoeven, M. G. Angew. Chem. Int. Ed. Eng., 1997, 36, 2329.

8 (a) Zhang, H.; Li, B.; Dikarev, E. V. J. Clust. Sci., 2008, 19, 311. (b) Pasko, S.; HubertPfalzgraf, L. G.; Abrutis, A.; Vaissermann, J. Polyhedron, 2004, 23 , 735. (c) Armstrong, A. R.; Bruce, P. G. Nature, 1996, 381, 499. (d) Pasko, S. V.; Hubert-Pfalzgraf, L. G.; Abrutis, 
A.; Richard, P.; Bartasyte, A.; Kazlauskiene, V. J. Mater. Chem., 2004, 14, 1245. (e) Tiitta, M.; Niinisto, L. Chem. Vap. Deposition., 1997, 3, 167. (f) Dahmen, K. H.; Carris, M. W. J. Alloys Comp., 1997, 251, 270.

9 (a) Bryant, J. R.; Taves, J. E.; Mayer, J. M. Inorg. Chem., 2002, 41, 2769. (b) Spencer, J. T. Prog. Inorg. Chem., 1994, 41, 145.

10 (a) Troyanov, S. I.; Gorbenko, O. Y.; Bosak, A. A. Polyhedron, 1999, 18, 3505. (b) Rüffer, T.; Joubert, C. C.; Buitendach, B. E.; Swarts, J. C.; Jakob, A.; Lang, H. Acta Cryst., 2011, E67, m231. (c) Rüffer, T.; Jakob, A.; Swarts, J. C.; Lang, H. J. Coord. Chem., 2013, 66, 329.

11 Zanello, P.; Fabrizi de Biani,F.; Glidewell, C.; Koenig, J.; Marsh, S. J. Polyhedron, 1998, 17, 1795.

12 (a) Zhuo, J. -B.; Li, H. -D.; Lin, C. -X.; Xie, L. -L.; Bai, S.; Yuan, J. -F. J. Mol. Struct., 2014, 1067, 112. (b) Buitendach, B. E.; Gągor, A.; Swarts, J. C. Inorg. Chem., 2013, 52, 10245. (c) Yu, J.; Shapter, J. G.; Johnston, M. R.; Quinton, J. S.; Gooding, J. J. Electrochimica Acta, 2007, 52, 6206. (d) LeSuer, R. J.; Geiger, W. E. J. Electroanal. Chem., 2006, 594, 20. (e) Hildebrandt, A; Schaarschmidt, D.; Van As, L.; Swarts, J. C.; Lang, H. Inorg. Chim. Acta, 2011, 374, 112.

13 (a) Conradie, J.; Swarts, J. C. Organometallics, 2009, 28, 1018. (b) Conradie, J.; Swarts, J. C. Dalton Trans., 2011, 40, 5844.

14 (a) Mino, T.; Segawa, H.; Yamashita, M. J. Organomet. Chem., 2004, 689, 2833. (b) Garabatos-Perera, J .R.; Butenschön, H. J. Mol. Cat. A: Chem., 2003, 196, 55.

15 (a) Swarts, P. J; Immelman, M.; Lamprecht, G. J.; Greyling, S. E.; Swarts, J. C. S. Afr. J. Chem. 1997, 50, 208. (b) Talawar, M. B.; Sivabalan, R.; Mukundan, T.; Muthurajan, H.; Sikder, A. K.; Gandhe, B. R.; Rao, A. S. J. Hazard. Mater., 2009, 161, 589. 
16 (a) Cheng, K.; Li, H.; Ng, D. K. P., J. Organomet. Chem., 2004, 689, 1593. (b) Hudson, R.

D. A.; Manning, A. R.; Nolan, D. F.; Asselberghs, I.; Van Boxel, R.; Persoons, A.; Gallagher, J. F. J. Organomet. Chem., 2001, 619, 141.

17 Spanig, F.; Kolvacs, C.; Hauke, F.; Ohlubo, K.; Fukuzumi, F.; Guldi, D. M.; Hirsch, A. J. Am. Chem. Soc., 2009, 131, 8180.

18 (a) Shago, R. F.; Swarts, J. C.; Kreft, E.; Van Rensburg, C. E. J. Anticancer Res., 2007, 27, 3431. (b) Gross, A.; Hüsken, N.; Schur, J. Raszeja, L.; Ott, I.; Metzler-Molte, N. Bioconjugate Chemistry, 2012, 23, 1764. (c) Swarts, J. C.; Vosloo, T. G.; Cronje, S. J.; Du Plessis, W. C.; Van Rensburg, C. E. J.; Kreft, E.; Van Lier, J. E. Anticancer Res., 2008, 28, 2781. (d) Maschke, M.; Max, L.; Metzler Nolte, N. Eur. J. Inorg Chem. 2012, 5953. (e) Ott, I.; Kowalski, K.; Gust, R.; Maurer, J.; Mücke, P.; Winter, R. F. Bioorg. Med. Chem. Lett, 2010, 20, 866 .

19 Gordy scale group electronegativities, $\chi \mathrm{R}$, are empirical numbers that express the combined tendency of a group of atoms, like $\mathrm{R}=\mathrm{CF}_{3}$ or ferrocenyl $(\mathrm{Fc})$, to attract electrons (including those in a covalent bond) as a function of the number of valence electrons, $n$, and the covalent radius, $\mathrm{r}(\AA)$, of groups as discussed in the following: (a) Wells, P. R. In Progress in Physical Organic Chemistry; John Wiley \& Sons, Inc.: New York, 1968; Vol. 6, pp 111-145 and (b) Kagarise, R. E. J. Am. Chem. Soc., 1955, 77, 1377.

20 Hessel, L. W.; Romers, C. Recl. Trav. Chim. Pays-Bas, 1969, 88, 545.

21 Gericke, H. J.; Muller, A. J.; Swarts, J. C. Inorg. Chem., 2012, 51, 1552.

22 (a) Dulatas, L. T.; Brown, S. N.; Ojomo, E.; Noll, B. C.; Cavo, M. J.; Holt, P. B.; Wopperer, M. M. Inorg. Chem., 2009, 48, 10789. (b) Erasmus, E.; Conradie, J.; Muller, A.; Swarts, J. C. Inorg. Chim. Acta, 2007, 360, 2277. (c) Prokop, P.; Quas, L.; Richter, R.; Dietze, F.; 
Beyer, L. Z. Anorg. Allg. Chem., 1999, 625, 1912. (d) Imai, H.; Ota, T. B. Bull. Chem. Soc. Jpn., 1974, 47, 2497. (e) Woisetschlager, O. E.; Geisbauer, A.; Polborn, K.; Beck, W. Z. Anorg. Allg. Chem., 2000, 626, 766.

23 (a) Bell, W.; Crayston, J. A.; Glidewell, C.; Mazid, M. A.; Hursthause, M. B. J. Organomet. Chem., 1992, 434, 115. (b) Woisetschläger, O. E.; Geisbauer, A.; Polborn, K.; Sünkel, K.; Beck, W. Z. Anorg. Allg. Chem., 1999, 625, 2164.

24 Van der Zeijden, A.A.H., Veghini, D., Berke, H. Inorg. Chem., 1992, 31, 5106

25 Smith, M. B; March, J., March's Advanced Organic Chemistry: Reactions, Mechanisms, and Structure, John Wiley and Sons: New York, 2001, 5th ed., pp 20-36.

26 Allen, F. H.; Kennard, O.; Watson, D. G.; Brammer, L.; Orpen, A. G.; Taylor, R. J. J. Chem. Soc., Perkin Trans., 1987, 2, S8.

27 Prescimone, A.; Sanchez-Benitez, J.; Kamenev, K. V.; Moggach, S. A.; Lennie, A. R.; Warren, J. E.; Murie, M.; Parsons, S.; Brechin,E. K. Dalton Trans. 2009, 7390.

28 (a) Du Plessis, W. C.; Davis, W. L.; Cronje, S. J.; Swarts, J. C. Inorg. Chim. Acta, 2001, 314, 97; (b) Von Chrzanowski, L. S.; Lutz, M.; Spek, A. L. Acta Crystallogr., 2006, E62, m3318. (c) Von Chrzanowski, L. S.; Lutz, M.; Spek, A .L. Acta Crystallogr., 2007, C63, m129.

29 Dexheimer, S. L.; Gohdes, J. W.; Chan, M. K.; Hagen, K. S.; Armstrong, W. H.; Klein, M. P. J. Am. Chem. Soc., 1989, 111, 8923.

30 Freitag R.; Conradie, J. J. Chem. Educ., 2013, 90, 1692.

31 (a) Freitag, R.; Muller, T. J.; Conradie, J. J. Chem. Crystallogr., 2014, 44, 352. (b) Langley, S. K.; Chilton, N. F.; Massi, M.; Moubaraki, B.; Berry, K J.; Murray, K. S. Dalton Trans., 2010, 39, 7236. (c) Stults, B. R.; Marianelli, R. S.; Day, V. W. Inorg. Chem., 1975, 14, 722. 
32 Du Plessis, W. C.; Erasmus, J. J. C.; Lamprecht, G. J.; Conradie, J.; Cameron, T. S.; Aquino, M. A. S.; Swarts, J. C. Can. J. Chem., 1999, 77, 378.

33 Manriquez, J.M.; Ward, M.D.; Reiff, W.M.; Calabrese, J.C.; Jones, N.L.; Carroll, P.J.;

Bunell, E.E.; Miller, J.S. J. Am. Chem. Soc., 1995, 117, 6182.

34 Biesinger, M. C.; Payne, B. P.; Grosvenor, A. P.; Lau, L. W. M.; Gerson, A. R.; Smart, St. C., R. Appl. Surf. Sci., 2011, 257, 2717.

35 Moulder, F.; Stickle, W. F.; Sobol, P. E.; Bomben, K. D. Handbook of X-ray Photoelectron Spectroscopy: a reference book of standard spectra for identification and interpretation of XPS data, ULVAC-PHI, Inc., Enzo, Chigasaki, Japan, 1995, pp. 45, 57, 143.

36 Connor, J. A.; Derrick, L. M. R.; Hillier, I. H. J. Chem. Soc., 1974, 70, 941.

37 Woodbridge, C. M.; Pugmire, D. L.; Johnson, R. C.; Boag, N. M.; Langell, M. A. J. Phys. Chem. B, 2000, 104, 3085 .

38 Trzebiatowska-Gusowska, M.; Gagor, A.; Coetsee, E.; Erasmus, E.; Swart, H. C.; Swarts, J. C. J. Organomet. Chem., 2013, 745, 393.

39 Kennedy, B.J.; Murry, K.S. Inorg. Chem., 1985, 24, 1552

40 Kowalczyk, S.P.; Lay, L.; McFeely, F.R.; Shirley, D.A., Phys. Chem. B, 1975, 11, 1721

41 Allen, G. C.; Harris, S. J.; Jutson, J. A.; Dyke, J. M. Appl. Surf. Sci. 1989, 37, 111.

42 Erasmus, J. J. C.; Lamprecht, G. J.; Swarts, J. C.; Roodt, A.; Oskarsson, A. Acta Crystallogr. 1996, C52, 3000 .

43 Charles, R. G. Inorg. Synth., 1963, 7, 183.

44 APEX2 (including SAINT and SADABS); Bruker AXS Inc., Madison, WI, 2012.

45 Sheldrick, G. M. Acta Crystallogr. 2008, A64, 112.

46 Farrugia, L. J. J. Appl. Crystallogr. 1997, 30, 565. 